CULTURE AND COOPERATION: EXAMINATION OF US-JAPAN DIFFERENCES IN THE FRAMEWORK OF UNCERTAINTY AVOIDANCE

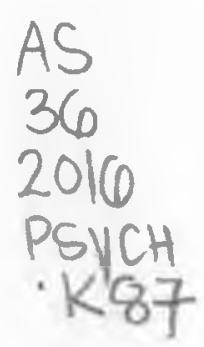

\author{
A thesis submitted to the faculty of \\ San Francisco State University \\ In partial fulfillment of \\ The requirements for \\ The degree \\ Master of Arts \\ In
}

Psychology: Social Psychology

by

Kodai Kusano

San Francisco, California

August 2016 
Copyright by Kodai Kusano 2016 


\section{CERTIFICATION OF APPROVAL}

I certify that I have read Culture and Cooperation: Examination of US-Japan Differences in the Framework of Uncertainty Avoidance by Kodai Kusano, and that in my opinion this work meets the criteria for approving a thesis submitted in partial fulfillment of the requirement for the degree: Master of Arts in Psychology: Social Psychology at San Francisco State University.

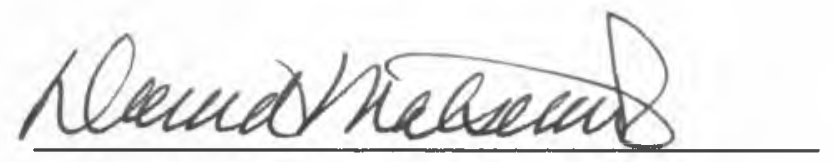

David Matsumoto, Ph.D.

Professor of Psychology

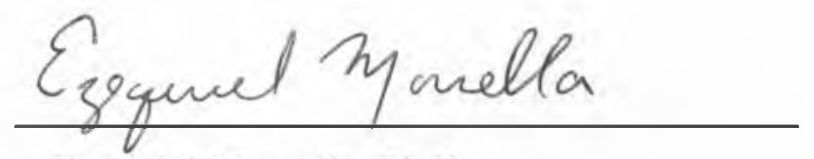

Ezequiel Morsella, Ph.D.

Associate Professor of Psychology 


\title{
CULTURE AND COOPERATION: EXAMINATION OF US-JAPAN DIFFERENCES IN THE FRAMEWORK OF UNCERTAINTY AVOIDANCCE
}

\author{
Kodai Kusano \\ San Francisco, California \\ 2016
}

The objective of this thesis was to examine whether uncertainty avoidance dimension of culture produces Unites State-Japan differences in cooperative behavior. I examined how uncertainty operated to produce cooperative behaviors differently between American and Japanese subjects. The subjects' cooperative behaviors were observed during the ultimatum game. Individual differences in individualism-collectivism, intolerance of uncertainty, and neuroticism were also measured as potential mediators or covariates of the effect of uncertainty and country on the cooperative behavior. Data showed that although there was no cultural difference on cooperative behaviors between Americans and the Japanese, uncertainty generally increased cooperative behaviors across cultures. The individual-level analysis also demonstrated that the Japanese had higher intolerance of uncertainty than did Americans. This thesis suggests that the uncertainty avoidance dimension is a useful cultural framework to explore cultural differences between Americans and Japanese in various domains of behaviors.

I certify that the abstract is a correct representation of the content of this thesis.

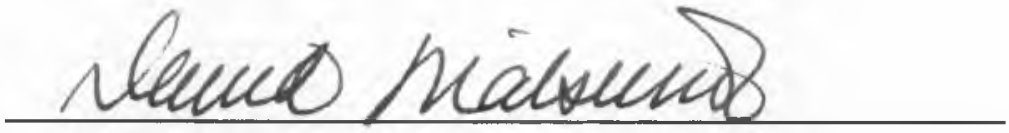

Chair, Thesis Committee

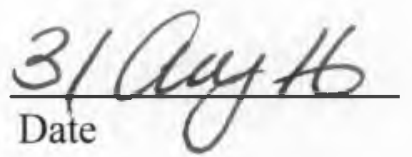




\section{ACKNOWLEDGEMENTS}

I would like to first thank my mentor, Dr. David Matsumoto, who taught me what it takes

to be a successful researcher throughout my education at San Francisco State University. I would like to give special thanks to Dr. David Shwalb, who connected me with San Francisco State University, where I found my passion and American dreams in the first place.

I would also like to thank my friends and teachers in the Culture and Emotion Research Laboratory at San Francisco State University - Jeff Spitzer Jr., Calen Horton, Annecy Majoros, Xiaoye Xu, Gerald Young, Nicholas Enfantino, Zubeda Khan, Erika Rauch, Roberto Orozco, and Dr. Seung Hee Yoo.

Finally, to my family - Mother, grandmother, father, and my sister. Without their supports, I would not have been able to meet these wonderful teachers and colleagues at San Francisco State University. 


\section{TABLE OF CONTENTS}

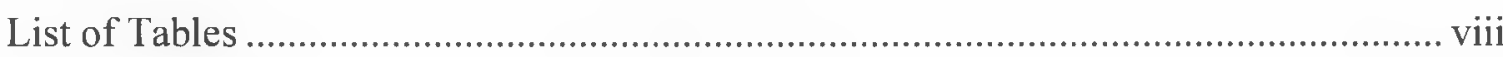

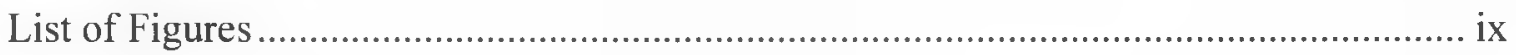

List of Appendices ………...........................................................................................



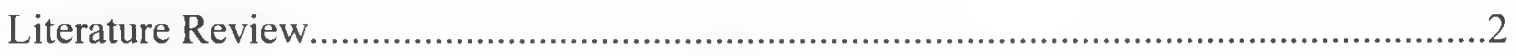

Studies Examining US-Japan Differences in Cooperation ......................................2

Inconsistency of the US-Japan Cross-Cultural Differences in Cooperation..............7

The Current Study - Revisiting the Uncertainty Avoidance Dimension................16

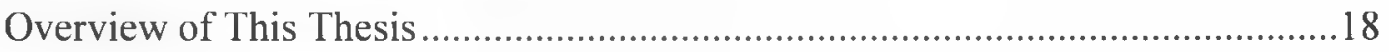



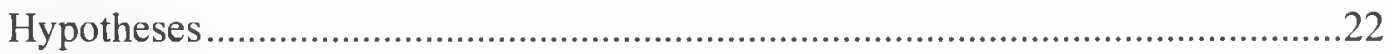

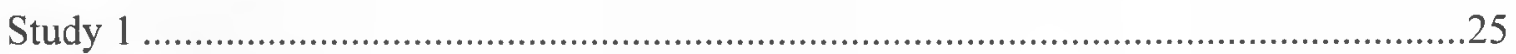

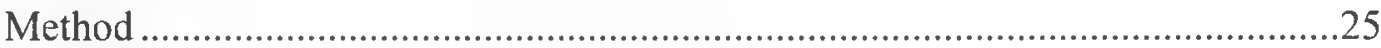





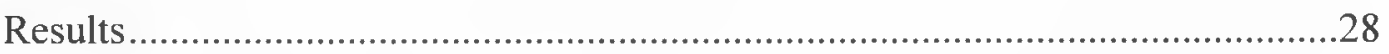

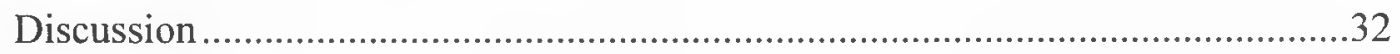

Study 2

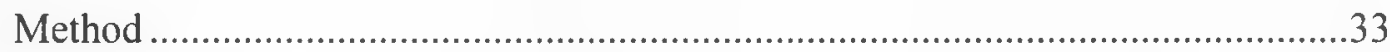

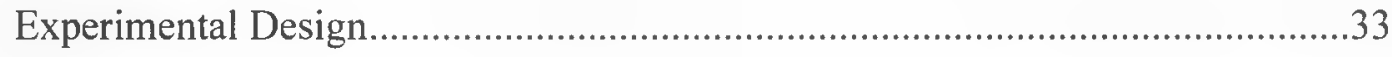


Participants

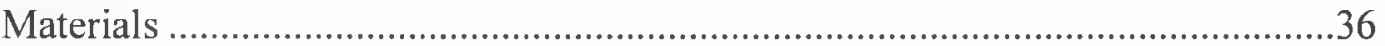

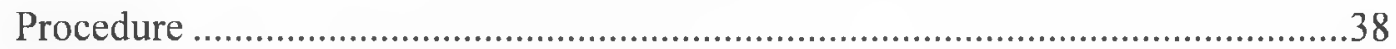



Individual-Level Analysis................................................................................44



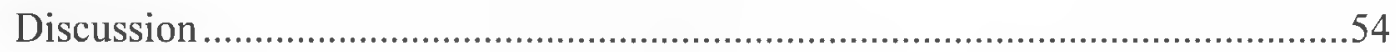

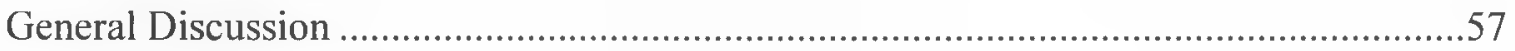

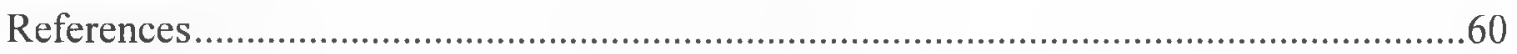

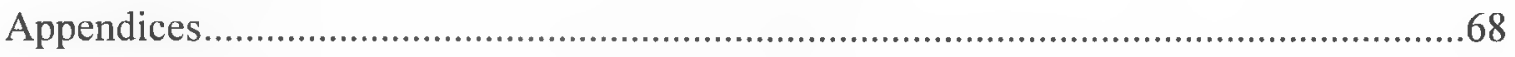




\section{LIST OF TABLES}

Table 1: Summary of US-Japan Differences on Cooperative Behaviors .8

Table 2: Certain and Uncertain Descriptions for Seven Contexts 26

Table 3: Mean Differences on Uncertain Adjectives between Uncertain Descriptions and Certain Descriptions

Table 4: Mean Differences on Aggregated Scores of Uncertain Adjectives between Uncertain Descriptions and Certain Descriptions

Table 5: Mean Differences on Aggregated Non-Uncertainty Scores between Uncertain Descriptions and Certain Descriptions.

Table 6: Participant Characteristics 36

Table 7: Reported Feelings on Each Adjectives between Uncertain Context and Uncertain Context

Table 8: Descriptive Statistics for Overall Reported Feelings on the Adjective Checklist

Table 9: Three-Way Interaction of Country x I/C x H/V

Table 10: Zero-Order Correlation between Individual-Level Variables

Table 11: Descriptive Statistics for Participants' Choice as a Responder during the Ultimatum Game 


\section{LIST OF FIGURES}

Figure 1: Overall Self-Reported Uncertainty between the Certain Condition and the Uncertain Condition

Figure 2: The Two-Way Interaction of Country and Context on the Amount of Money Participants Proposed to Another Partner during the Ultimatum Game .51

Figure 3: Participants' Choice as to Accept or Reject an Unfair Offer by Another Partner during the Ultimatum Game ..... .54 


\section{LIST OF APPENDICES}

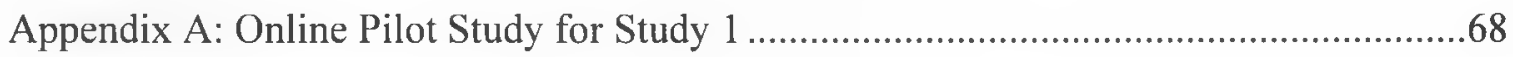

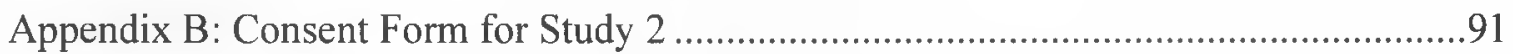

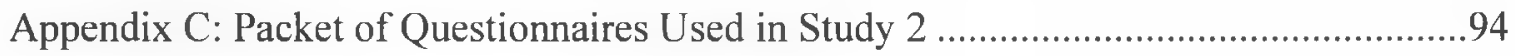

Appendix D: Instruction for the Ultimatum Game ……….............................................99

Appendix E: Follow-Up Questionnaire in Study 2 2....................................................106

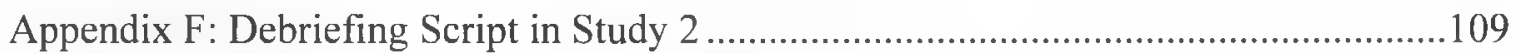




\section{Introduction}

Cooperation is an essential component of human socialization. In this thesis, cooperation is broadly defined as people's behavior enacted to work together toward collective goals. Recently, social scientists began to explore variations in human cooperation throughout the world. In particular, experimental game studies documented a number of differential patterns in cooperative behaviors across cultures (Henrich et al., 2001). Of the many developed countries studied in the cross-cultural literature, in general, US-Japan studies stood out as the most popular cross-cultural comparison (Oyserman, Coon, \& Kemmelmeier, 2002). Historically, the Individualism-Collectivism (IC) framework has dominated the way researchers compare individuals from cultures of West and East in psychological research. Accordingly, some researchers attributed observed US-Japan differences in cooperative behaviors to cultural differences in their IC orientations. A close review of the literature, however, implies that the IC framework may be inadequate in accounting for US-Japan differences in cooperative behavior. Surprisingly, little research in cross-cultural psychology has considered alternate frameworks that could explain US-Japan differences in psychological processes. This is a major limitation in the field.

The current thesis describes two studies that attempt to address this limitation. The first section reviews previous studies that examined US-Japan differences in cooperative behaviors. The second section introduces the IC framework and describes how observed US-Japan differences in research on cooperation have been interpreted by 
this framework. The third section examines some of the possible limitations of applying the IC framework to the study of US-Japan differences. The fourth section introduces the Uncertainty Avoidance (UA) dimension and discusses why the UA dimension, instead of

the traditional IC framework, is an important cultural dimension that may help to explain US-Japan differences in cooperative behavior. The next section sets up the overview of the current study and formulates hypotheses. The first study aims at creating priming stimuli that can be used to elicit uncertainty. The second study tested the hypotheses by experimentally investigating the effect of uncertainty on cooperative behaviors between Americans and Japanese. The final section of the thesis discusses limitations of the current thesis, implications of the findings, and possible directions for future research.

\section{Literature Review}

\section{Studies examining US-Japan differences in cooperation}

Within the cross-cultural research literature on cooperation, many behavioral experiments investigated differences between Americans and Japanese. One prominent paradigm in this line of research is the prisoner's dilemma (PD) game. A typical prisoner's dilemma game has the following four features: (a) each player simultaneously chooses to either cooperate or defect; (b) a defecting player can receive maximum individual benefit if the other player cooperates; (c) maximum collective benefits occur when both players cooperate; (d) the worst payoff for each player results when both players defect. Hayashi, Ostrom, Walker, and Yamagishi (1999) compared American and 
Japanese responses in the one-shot PD game; they found no difference between Americans and Japanese under normal conditions. In the experimental conditions, however, the researchers manipulated the sense of control by creating two additional features: (1) whether or not the first player's decision was transparent to the other partner (knowledge/no-knowledge); (2) whether the subject made a decision before the other partner (self-first/other-first). The researchers found that, in the self-first/knowledge condition, a greater percentage of Japanese participants (83\%) cooperated than did their American counterparts (56\%). In contrast, in the other-first/no-knowledge condition, a greater proportion of American participants (38\%) cooperated than did their Japanese counterparts $(12 \%)$. These results, taken together, suggested that the Japanese were more cooperative than were the Americans when they perceived a higher sense of control during the decision process. On the other hand, the sense of control played a less important role for Americans' cooperation.

Some researchers shed light on US-Japan differences in cooperation using a modified version of the PD game which they called "trust game." In the trust game, the decision phase between two players is separated into two separate parts: trusting and cooperating. In the first part, the two players announce how much money they are willing to entrust to each other. In the second part, both players are informed of the amount of money announced and simultaneously choose whether or not to return the money. In the case of a return, the receiver earns double the amount of money he/she announces in the first phase. The first phase in the decision process reflects trusting and risk-taking, as 
entrusting more money could increase the chances of being exploited. The second phase is a more direct index of cooperative behavior. Under the aforementioned rule, Cook et al. (2005) compared Americans and Japanese participants and found that the Americans took more risks by entrusting more money than did the Japanese, with both fixed and random partners. Moreover, the opportunity to entrust increased the Americans' cooperation in the second phase, but it did not increase Japanese cooperation. The Americans, driven by their higher willingness to take risks in interpersonal interactions, cooperated more than did the Japanese.

In a similar vein, Mashima, Yamagishi, and Macy (2004) conducted a repeated trust game, in which Americans and Japanese played against each other across countries over the internet. In one condition, subjects knew the nationality of the other player (U.S. vs. Japan), whereas in the other condition subjects knew no such information. Across the conditions, the researchers found no differences in the mean level of cooperative behaviors between Americans and Japanese. Numerous other studies compared Japanese with other Western subjects in the trust game paradigm and documented group differences; Japanese subjects were less cooperative than Australians regardless of ingroup/out-group distinction of their partners (Yamagishi et al., 2005); Japanese subjects were less cooperative than were New Zealanders (Yamagishi, Mifune, Liu, \& Pauling, 2008).

Another paradigm in the study of cooperation has used the social dilemma game, which would allow researchers to observe cooperative behavior in a group context 
consisting of multiple players. The social dilemma includes the following two features: (a) each individual gains higher rewards by acting on self-interest over others; however, (b) collective non-cooperative acts result in greater harms than a benefit gained by each self-interested act (Dawes, 1980). Since the social dilemma involves multiple players, it reflects dilemmas relevant to resource and public goods. In one of the earliest crosscultural experiments using social dilemma, Yamagishi (1988) compared cooperative behaviors of Americans and Japanese and found that the Japanese were less cooperative than were the Americans. However, when a sanctioning system took effect, the group difference between Americans and Japanese disappeared. This result implied that the presence of a sanctioning system increased the Japanese cooperative behaviors, whereas it didn't for the Americans. Similarly, Wade-Benzoni et al. (2002) conducted a resource dilemma game between Americans and Japanese. In contrast with the study by Yamagishi (1998), the researchers found that the Japanese exhibited greater cooperative behaviors than did the Americans.

Other researchers have examined US-Japan differences in cooperation in relation to allocating behavior. One major line of research involves the ultimatum game (Güth, Schmittberger \& Schwarze, 1982). The ultimatum game is played by a pair of subjects a proposer and a responder. One player, who serves as a proposer, is first given a certain amount of money. The proposer's job is to divide that money with another partner, who is the responder. After the proposer divides the money, the responder is informed of the amount of the offer and asked to choose to either accept or reject the offer. If the 
responder accepts the offer, both players get the money as proposed; in the case of rejection, neither of the players get the money. Roth, Prasnikar, Okuno-Fujiware, and Zamir (1991) compared cooperative behaviors of individuals in the U.S., Japan, and Yugoslavia in the ultimatum game and found that U.S. individuals proposed higher offers than did Japanese individuals. On the other hand, Buchan, Croson, and Johnson (2004) reported a reverse pattern, with Japanese proposing higher offers than Americans. Some researchers examined US-Japan differences in allocating behaviors using reward allocation tasks. In contrast with the ultimatum game, reward allocation reflects one's perception of equality and equity. Kim, Park, and Suzuki (1990) investigated preferences of reward allocation between Americans and Japanese using a scenario method: a hypothetical group project in a university class, in which students were asked to allocate percentage of grades among themselves and a hypothetical group member, A. The researchers found that regardless of the degree of task inputs and cooperative attributes of the member A, Americans reported more generous reward allocations to the member A than did the Japanese.

Cooperation has also been studied in the context of the trading market paradigm. In this paradigm, researchers observe cooperative behaviors in a dyad consisting of a "buyer" and a "seller." Using this paradigm, Yamgishi, Cook, and Watabe (1998) compared commitment formation of Americans and Japanese. In their experiment, subjects played a role of "buyer" to trade goods with two "sellers." Buyers were to buy a commodity from one of the two sellers in each session. The true price of each commodity 
was covered at the moment of trading. At the end of each session, the experimenter, who had information about the real price of the commodity, would buy the goods the buyers purchased from each session. Buyers were told that they would make profits if the actual prices were lower than the real prices at the end of the experiment. In the experimental condition, the researchers inserted a roulette that would randomly give the sellers a chance to steal the predetermined money of the buyers at any given time. One of the sellers was set up to always use this chance. The other seller, a "trustworthy" seller, would never use this chance. The dependent variable (commitment formation) in the game was measured as the frequency of trading with the trustworthy seller in the last 10 sessions. Under the aforementioned rule, the researchers found that there were no crosscultural differences between Americans and Japanese on the frequency of commitment formation; however, there was a main effect of the roulette, suggesting that both Americans and Japanese tended to make more commitment with the trustworthy seller when there was a possibility of being robbed. These findings were consistent with Kollock's assertion that when "faced with a situation in which one can be taken advantage of, the natural response is to restrict one's transactions to those who have shown themselves to be trustworthy (i.g., becoming committed to particular exchange partners)." (1994, p.318).

\section{Inconsistency of the US-Japan cross-cultural differences in cooperation}

As reviewed above, researchers compared the cooperative behaviors of Americans and Japanese in many different behavioral experiments and have documented 
interesting group differences (see Table 1 for the summary). One may notice, however, that the US-Japan differences are inconsistent across studies. For instance, Wade-Benzoni et al. (2002) and Buchan et al. (2004) documented that the Japanese showed higher cooperative behavior than did the Americans. Other studies showed otherwise; the Americans endorsed greater cooperative behaviors than did the Japanese (Hayashi et al., 1999; Kim et al., 1990; Roth et al., 1991), and others showed non-significant differences (Mashima et al., 2004; Yamagishi et al., 1998). In some studies, the direction of USJapan differences in cooperation depended on the conditions of games in which the participants' behaviors were measured (Hayashi et al., 1999; Yamagishi, 1988).

Table 1

Summary of US-Japan Differences on Cooperative Behaviors

\begin{tabular}{|c|c|c|}
\hline \multirow[b]{2}{*}{ Task } & \multicolumn{2}{|l|}{ Main Finding } \\
\hline & Condition & $\begin{array}{c}\text { US-JP } \\
\text { Difference }\end{array}$ \\
\hline $\begin{array}{c}\text { One-shot prisoner's dilemma } \\
\text { (Hayashi, Ostrom, Walker, } \\
\text { Yamagishi, 1999) }\end{array}$ & $\begin{array}{l}\text { Control } \\
\text { Self-first/Knowledge } \\
\text { Other-first/No-knowledge }\end{array}$ & $\begin{array}{c}\mathrm{NS} \\
\mathrm{US}<\mathrm{JP} \\
\mathrm{US}>\mathrm{JP}\end{array}$ \\
\hline $\begin{array}{c}\text { Trust game } \\
\text { (Cook, Yamagishi, Cheshire, } \\
\text { Cooper, Matsuda, Mashima, } \\
\text { 2005) }\end{array}$ & $\begin{array}{l}\text { Random partner } \\
\text { Fixed partner }\end{array}$ & $\begin{array}{l}\mathrm{US}>\mathrm{JP} \\
\mathrm{US}>\mathrm{JP}\end{array}$ \\
\hline $\begin{array}{c}\text { Trust game } \\
\text { (Mashima, Yamagishi, \& Macy, } \\
\text { 2004) }\end{array}$ & $\begin{array}{l}\text { Display of partner's nationality } \\
\text { No information of partner's nationality }\end{array}$ & $\begin{array}{l}\text { NS } \\
\text { NS }\end{array}$ \\
\hline
\end{tabular}


Social dilemma

(Yamagishi, 1988)

Social dilemma

(Wade-Benzoni, Okumura, Brett, Moore, Tenbrunsel,

Bazeman, 2002)

Ultimatum game

(Buchan, Croson, \& Johnson, 2004)

Ultimatum game

(Roth, Prasnikar, Okuno-

Fujiware, \& Xamir, 1991)

Reward allocation

(Kim, Park, and Suzuki, 1990)
Sanctioning

No sanctioning

NS

$\mathrm{US}>\mathrm{JP}$

None

$\mathrm{US}<\mathrm{JP}$
Control

High buyer's (proposer's) power

$\mathrm{US}<\mathrm{JP}^{*}$

$\mathrm{US}<\mathrm{JP}^{*}$

High input of member A

Intermediate input of member $A$

Low input of member $A$

$\mathrm{US}>\mathrm{JP}$

$\mathrm{US}>\mathrm{JP}$

$\mathrm{US}>\mathrm{JP}$

High maintenance input of member A

Intermediate

Low

$\mathrm{US}>\mathrm{JP}$

$\mathrm{US}>\mathrm{JP}$

$\mathrm{US}>\mathrm{JP}$

$\mathrm{US}>\mathrm{JP}$

Exchange goods

(Yamagishi, Cook, \& Watabe,

High social uncertainty

NS 1998)

Low social uncertainty

NS

Note. NS $=$ No significant differences. ${ }^{*}=$ No statistical significance was provided

IC framework. How can one interpret these inconsistent results? One dominant framework in explaining cultural differences between the U.S. and Japan is the Individualism-Collectivism (IC) framework. When conducting cross-cultural research 
involving US-Japan comparisons in general, many researchers have assumed that the U.S. is an individualistic nation and Japan is a collectivistic nation. Traditionally, scholars have often portrayed the Japanese culture as collectivistic, as opposed to the American individualistic culture (Benedict, 1946; Doi, 1973; Lebra, 1976). These writers, for instance, have claimed that, in American culture, people emphasize independence and uniqueness over group orientations while, on the other hand, in Japanese culture people value harmony with others and obligation to groups over self-interests. These claims seemed to receive empirical support from scientific research that focused on the dimension of individualism. The emergence of the term individualism in cross-cultural research dates back to Geert Hofstede's groundbreaking work, Culture 's Consequences (1980). In the book, Hofstede analyzed a large-scale survey data from a multinational corporation HERMES (now known as IBM) and reported work-related values of the employees between 1967 and 1973 in 40 countries. His factor analysis on the survey data generated four dimensions: individualism, power distance, uncertainty avoidance, and masculinity. On the dimension of individualism, the U.S. was ranked $1^{\text {st }}$, and Japan was ranked $24^{\text {th }}$, below all other Western countries, including Australia, Great Britain, Canada, the Netherlands, and New Zealand. In Hofstede's analysis, Individualism refers to the degree to which a society places higher preference for loosely-tied networks in which personal goals are valued over group cause. Its opposite, Collectivism, refers to the degree to which a society prefers tightly-knit groups in which in-group loyalty is valued over individual preference (Hofstede, 1980). Of the four dimensions, a substantial 
number of cross-cultural research has used the individualism dimension as a primary framework to interpret and predict cultural differences in many country comparisons.

Markus and Kitayama (1991) further declared that behavioral differences between Americans and Japanese could be explained by the way that individuals define themselves in relation to others. Their theory claims that people of Western cultures, presumably individualistic cultures, tend to possess an independent self, in which the self is defined independently of others. The independent self is constructed through cultural socializations which expect individuals to stand out. In contrast, people of East Asian cultures, presumably collectivistic cultures, tend to possess an interdependent self, in which the self is defined in relation to others. The interdependent self is constructed through cultural socializations that expect individuals to fit in. The US-Japan comparison has often been cited as a classic example of cross-cultural comparison in the context of the West and the East, to which the self-construal theory applies. For example, Markus and Kitayama (1991) noted: "In America, 'the squeaky wheel gets the grease.' In Japan, 'the nail that stands out gets pounded down."' (p. 224). This anecdote illustrates the underlying logic of the theory: Western societies and East Asian societies differ in their relative degree of individualistic/collectivistic socializations, which as a result produce distinct self-construals that fundamentally shape individuals' psyches. Modern experts in the cultures of the U.S. and Japan have also agreed that, compared to the American individualistic culture, the Japanese culture is best considered collectivistic (Heine, Lehman, Peng, \& Greenholtz, 2002). Based upon the works described above, the 
"Individualism-Collectivism" (IC) framework has become one of the most popular focuses of cross-cultural research (Oyserman, Coon, \& Kemmelmeir, 2002; Taras, Kirkman, \& Steel, 2010). Many researchers have advocated the IC framework as a primary predictor of US-Japan differences in various domains of behavior, such as emotion (Markus \& Kitayama, 2001), motivation (Iyengar, \& Lepper, 1999), well-being (Oishi, Diener, Lucas, \& Suh, 1999; Kitayama, Markus, \& Kurokawa, 2000), and cognition (Nisbett, Peng, Choi, \& Norenzayan, 2001).

In the same way, some researchers have accounted for US-Japan differences in cooperative behaviors under the IC framework. According to the IC framework, individualists (Americans) are less concerned with the consequences of their actions on the social environment and more concerned with their self-interest over that of the group, whereas collectivists (Japanese) are more concerned with group obligation and sacrificing self-interest in favor of group interests. Wade-Benzoni et al. (2002; see Table 1), for example, found that Japanese endorsed less individualistic responses on the "I am" questionnaires than did Americans and used this evidence to interpret the observed finding that the Americans were less cooperative than were the Japanese. Indeed, the researchers explicitly concluded that "Japanese decision makers seemed to construe the social dilemma as an interdependent situation, to be highly attuned to the interests of others in the group (collectivism), and to be willing to take on burdens that were greater than their share (hierarchy) in order to manage the sustainability of the resource. Groups of U.S. decision makers, on the other hand, seemed to act quite independently 
(individualistic) and defensibly (egalitarian) until they had the opportunity to communicate (Wade-Benzoni et al., 2002)." Although the rationale of the IC framework was not made explicitly, some experiments produced US-Japan differences in cooperative behaviors consistent with Wade-Benzoni et al. (2002). (see Table 1; Hayashi et al., 1999; Buchan et al., 2004).

Can the IC framework consistently predict the US-Japan differences in cooperation? Indeed, interpretations of other findings have been mixed. The study by Kim et al. (1990), for example, relied on the IC framework to predict differences in reward allocations between Americans and Japanese, but they found inconsistent findings, such that the Japanese exhibited the least generous behaviors compared to individuals of Korea and the U.S. They concluded that the competitive nature observed among the Japanese was perhaps driven by their high levels on the masculinity dimension or by developed industrialization in the Japanese society. Another line of research led by Yamagishi and his colleagues demonstrated that the US-Japan differences, with Japanese being less cooperative than Americans, were produced by the difference in the level of general trust: Japanese were typically less willing to trust strangers than did Americans (Yamagishi, 1988; Hayashi et al., 1999; Cook et al., 2005). These studies producing nonsignificant US-Japan differences do not support the IC framework in accounting for USJapan differences in cooperative behavior.

Limitations in the IC framework. The IC framework seems to have gained popularity in the literature of cross-cultural studies in U.S. and Japan. Despite the 
popularity, as described in the previous section, the IC does not seem to be the primary source of US-Japan difference in cooperative behavior. A major limitation in the literature is that the field lacks an alternative framework to explain the observed USJapan differences in cooperation. Prior to discussing how the current study addresses this limitation, this section describes three potential limitations which call into question the use of the IC framework as the primary account for observed US-Japan differences in cooperative behavior.

The first limitation may speak to the weak association between individualism and cooperative behavior. A meta-analysis by Oosterbeek, Sloof, and van de Kuilen (2004) showed that the relationship between cooperative behaviors in the ultimatum game (offer by a proposer) and the Hofstede's individualism index across 25 countries, including the US and Japan, was negligible. In many cases, researchers implicitly assumed that differences in IC values existed between Americans and Japanese and related the group difference to the observed behaviors. Nevertheless, the existence of group differences itself, without an empirical assessment of beliefs, values, or attitudes relevant to the IC, cannot justify the direct link between the IC dimension and cooperative behaviors. To date, the only study that investigated such a link is the study by Wade-Benzoni et al. (2002), who demonstrated that cross-cultural differences in the responses to the "I am" questionnaire were linked with the US-Japan difference in cooperative behaviors. The lack of convincing evidence supporting the link between individualism and cooperation may account for the conflicting findings summarized in Table 1 . 
The second limitation relates to the possibility that the very notion that Americans are more individualistic (independent) than Japanese is false (Takano \& Osaka, 1999). Matsumoto (1999) argued that to attribute observed group differences between Americans and Japanese to cultural differences in the IC orientations, one needs to ensure that individuals from the two cultures systematically differ on the IC values in the predicted direction. However, there has been little work directly testing this assumption, and works that assessed the assumption failed to provide empirical supports for the common notion. Oyserman et al. (2002) conducted a comprehensive meta-analysis to examine the assumptions of the IC framework in US-Japan comparisons; they metaanalytically compared mean differences generated by cross-cultural studies using IC measurements and concluded that Americans were generally more collectivistic than Japanese. A further analysis indicated that US-Japan differences in IC values were moderated by the content of the IC measurements. For example, Americans were more individualistic than Japanese by only small effect size on the overall individualism. However, when personal uniqueness was removed as a factor of IC dimension, Japanese appeared to be more individualistic than Americans; moreover, when competitiveness was included as a factor, there was no difference between Americans and Japanese. A recent meta-analysis conducted by Taras et al. (2014) on the dimensionality of the IC construct at the individual-level also supported the inconsistency of differences between Americans and Japanese on the IC values. The researchers found that constructs of individualism and collectivism were generally orthogonal to each other at the individual 
level: that is, individuals regardless of cultures could simultaneously hold attitudes of both individualism and collectivism. Their study also indicated that the plain individualism-collectivism (independent-interdependent) dichotomy often exercised by many researchers was no longer warranted when comparing individuals of Western and Eastern cultures. In addition to these survey-based findings, behavioral studies on conformity (Takano \& Sogon, 2008) and preference for uniqueness (Yamagishi, Hashimoto, \& Schug, 2008) demonstrated that Japanese were no more collectivistic than Americans. Some also argued that, at the societal level, Japan became more individualistic than it was once assumed to be, as well (Hamamura, 2012; Matsumoto, 2007). Taken together, existing empirical data strongly suggest that the underlying assumptions of the IC framework in interpreting US-Japan differences are unwarranted.

The third limitation is that, although some experiments documented US-Japan differences in cooperative behavior in the predicted direction, the IC dimension may not be the only dimension at work which produces cultural differences. The two cultures also differ on other cultural dimensions (Hofstede, 1980) and non-cultural variables such as personality traits, which could potentially produce US-Japan group differences (Matsumoto, 2008). Works examining alternative factors are scarce. The current study directly addresses this limitation by focusing on an alternative cultural dimension called uncertainty avoidance.

\section{The current study - Revisiting the uncertainty avoidance dimension}


Despite the field's enthusiasm, the IC framework is far from being satisfactory as a primary account for the previous US-Japan differences in cooperative behaviors. The IC framework especially falls short if Americans and Japanese do not differ on the IC dimension. Instead of relying on the IC framework, the current thesis explores another dimension of culture that may be operating to produce US-Japan differences: the uncertainty avoidance dimension.

Uncertainty avoidance (UA) dimension refers to the degree to which, at the societal level, people feel threatened by uncertainty and establish rules to minimize threats (Hofstede, 1980; Hofstede, 2001; Hofstede \& McCrae, 2004). Traditionally, Japan has been higher than the U.S. on this dimension (Hofstede, 1980; Hofstede, 2001). Recall that in the trust game conducted by Cook et al. (2005; see Table 1), Americans, compared with the Japanese, took greater risks to show signals of trust and built more cooperative relationships with their partners. The researchers used the UA dimension as a basis to interpret the observed US-Japan group differences in the risk-taking behaviors and cooperative processes, since individuals in societies high in UA (e.g., Japan) are less willing to take personal risks than those in societies low in UA (e.g., U.S.) (Hofstede, 1980). The researchers speculated that US-Japan group differences in cooperative behavior may be driven by the consistent differences in levels of UA, which produces different levels of tolerance towards risk-taking in each society. The explanation holds for numerous other experiments demonstrating that Japanese were generally less cooperative than Americans (see Table 1). 


\section{Overview of this thesis}

The purpose of the current thesis was to test whether the UA dimension causes US-Japan differences in cooperative behaviors. An important framework underlying the current experiment is the "culture as a situated cognition" approach (Oyserman \& Lee, 2008). The theory asserts that priming individuals with cultural cues would allow researchers to observe the causal effect of cultural meaning on subsequent behaviors. For example, individuals primed with individualism were shown to behave in individualistic ways in subsequent tasks regardless of their cultural heritage (Oyserman \& Lee, 2008). Using this framework, the current thesis more directly takes into consideration the operationalization of UA as originally proposed by Hofstede: in cultures high in uncertainty avoidance, individuals are more exposed to environmental threats and more likely to feel distressed by uncertainty (Hofstede, 1980). The current experiment sought to prime subjects with uncertainty by manipulating context in order to draw a causal implication of the UA dimension on the subsequent cooperative behaviors.

The ultimatum game. The current experiment measured cooperative behaviors using the ultimatum game (UG: Güth et al.,1982). People who play a responder are generally willing to punish a proposer if he/she provides an unfair offer that is below $25 \%$ of the available money (Fehr \& Fischbacker, 2003). Thus, the UG provides a unique context in which a proposer faces fear of rejection when cooperating. A generous offer would decrease the possibility of rejection, while a selfish offer would increase the 
possibility of rejection. Higher uncertainty may increase the fear of rejection and lead a proposer to offer more generous amount to his/her partner.

In the current experiment, two major modifications were made to the UG. First, an automated computer served as the subjects' partner, so that the subjects played the UG independently. The computer's decisions were held constant across subjects; it was preprogrammed to offer an unfair offer ( $20 \%$ of the distributed money) as a proposer and to always accept the subjects' offers as a responder. Thus, the current experiment eliminated the effect of dyadic interaction between subjects. The second modification was that the subjects in the current experiment played two trials and served both roles of a proposer and a responder. Given the aforementioned modifications, the current experiment sought to measure cooperative behaviors in two ways: (1) the amount of money that subjects offered as a proposer; and (2) whether the subjects accepted the unfair offer proposed by their partner.

Linkage approach. To attribute group differences between Americans and Japanese to cultural differences, it is desirable to empirically measure and control for individual-level variables, which could alternatively produce the group differences (Matsumoto \& Yoo, 2006). The cornerstone of such a linkage approach is to conceptually separate culture from non-cultural variables by defining it. Thus, culture was defined as meaning and information system shared by a group of people (Matsumoto \& Juang, 2013). The current experiment measured individual differences in two cultural variables (IC values and intolerance of uncertainty) and one personality variable (neuroticism) as 
potential mediators or covariates of the effect of uncertainty and country differences in cooperative behaviors.

IC values. The current study assessed individual-level IC attributes on Horizontal-Collectivism (HC), Vertical-Collectivism (VC), Horizontal-Individualism (HI), and Vertical-Individualism (VI) (HVIC; Singelis, Triandis, Bhawuk, \& Gelfand, 1995; Triandis, 1995; Triandis \& Gelfand, 1998). Psychological characteristics of HC include interdependence and harmony with in-group members. VC reflects values on tradition and acceptance of hierarchy within the group. HI includes the desire to be unique and different from others. VI refers to the acceptance of inequality and emphasis on competition. In short, the vertical and horizontal dimensions allow for the quantification of nuances of hierarchy (vertical) and inequality (horizontal) in the IC framework. As Americans and Japanese have been found to differ on distinct aspects of the IC values (Oyserman et al., 2002), examining IC values using a more fine-grained approach would be appropriate for the current study. Moderate scale reliability and validity coefficients with authoritarianism among U.S. and Japanese samples were demonstrated by a previous study in both English and Japanese, respectively (Kemmelmeier et al., 2003).

Intolerance of uncertainty. The current study assessed the intolerance of uncertainty as an individual-level UA variable (Buhr \& Dugas, 2002; Freeston et al., 1994). The construct refers to one's negative evaluation of uncertainty in the following four domains: perception of uncertainty as stressful, attitude toward the effect of 
uncertainty on one's welfare, tendency to avoid uncertainty, and perception of the unfairness of being uncertain about one's future. Intolerance of uncertainty was shown to be positively associated with social anxiety among European Canadian and Japanese samples in both respective languages (Zhou et al., 2014). Zhou et al. (2014) found that Japanese showed higher intolerance of uncertainty than European Canadians and Chinese.

Neuroticism. Another relevant factor that may produce a US-Japan group difference is neuroticism. Neuroticism generally refers to one's dispositional tendency to feel negative affect such as anxiety, stress, and anger. Previous studies on the Big Five Personality Model have documented consistent differences between Japanese and North Americans on the trait of Neuroticism, with Japanese demonstrating higher neuroticism than North Americans (Allik \& McCrae, 2004; McCrae et al., 2005). Matsumoto (2008) demonstrated that a US-Japan group difference in emotion regulation was entirely mediated by the individual differences in neuroticism, extraversion, and conscientiousness. Moreover, neuroticism positively correlated with the UA dimension at the country-level (Hofstede \& McCrae, 2004). The current study attempted to extend the link between the two constructs at the individual-level. In doing so, the current study assessed the N-domain of the NEO-FFI-3 (Costa \& McCrae, 1992). The structural equivalence and cross-cultural construct validity in both English and Japanese were established by previous research (Allik, \& McCrae, 2004; Costa \& McCrae, 1992; McCrae et al,, 2005). 


\section{Overview and hypothesis}

The purpose of the current thesis was to investigate the causal effect of the UA dimension on cooperative behaviors and to test whether the UA would produce JapanU.S. cultural differences in cooperative behaviors. The current thesis had two independent studies.

Study 1. Study 1 was a pilot study in order to create uncertainty primes that could be embedded in the context of the ultimatum game in Study 2. Participants in the Study 1 completed an online survey in which they evaluated several contexts in a hypothetical psychological experiment on the basis of how they would feel in each context. Since this pilot study was specifically designed for use in Study 2, there were no specific hypotheses.

Study 2. Study 2 investigated whether uncertainty would produce US-Japan cultural differences in cooperative behaviors in the ultimatum game. Study 2 implemented uncertainty priming stimuli created using the results of Study 1 as experimental manipulations during the ultimatum game. The experiment employed a linkage approach, such that individual differences in IC values, intolerance of uncertainty, and neuroticism were measured as potential mediators or covariates of the effect of uncertainty primes and US-Japan group differences on cooperative behaviors.

\section{Hypotheses}


Individual-level analysis. Consistent with the literature regarding individual differences in US-Japan comparison, the following five hypotheses were tested:

1. Japanese would score higher on neuroticism than Americans.

2. Japanese would score higher on intolerance of uncertainty than Americans.

3. Americans would score higher on individualistic values than Japanese when uniqueness is included as an attribute of individualism (horizontalindividualism).

4. Japanese would score higher on individualistic values than Americans when uniqueness is removed as an attribute of individualism (verticalindividualism).

5. Americans would score higher overall on collectivistic values than Japanese.

Experiment on cooperation. Previous studies have shown that fear of punishment increases cooperative behaviors. Similarly, uncertainty has been shown to increase mutual commitment between dyads. In the ultimatum game, a proposer faces uncertainty as to whether their offer may be rejected. Therefore, the current experiment sought to manipulate uncertainty and tap into the fear of rejection and mutual commitment. Consistent with the previous studies on cooperation and uncertainty in USJapan comparisons, the following two hypotheses were generated: 
6. Individuals primed with uncertainty in the ultimatum game would show greater cooperative behaviors than those primed with none.

7. If Japanese would score higher on neuroticism and intolerance of uncertainty than Americans, Japanese would be more vulnerable to uncertainty priming. Thus, Japanese primed with uncertainty would exhibit greater cooperative behaviors than Americans primed with uncertainty. 


\section{Study 1}

\section{Method}

Study 1 was conducted to create experimental manipulations that could be used in Study 2. The purpose of the manipulations was to examine the causal effect of the uncertainty avoidance as a contextual-level variable on cooperation. The idea was consistent with the culture as situated cognition approach (Oyserman \& Lee, 2008), which asserted that priming with contextual cues associated with cultural themes would allow one to imply causal effects of the cultural meaning on the observed psychological outcomes. Candidates of uncertain contexts were specifically created for the experimental condition of the Ultimatum Game (Güth et al., 1982), which was used to measure participants' cooperative behaviors in Study 2. Study 1 was a survey that asked respondents to rate several descriptions about contexts in a hypothetical psychological experiment.

Context construction. Seven candidate contexts, specifically designed for the Ultimatum Game situation, were first created. For each context, certain and uncertain descriptions were made up as a pair. Thus, the survey contained total of 14 descriptions to be rated. The descriptions used in each seven contexts are provided in Table 2. 
Table 2

Certain and Uncertain Descriptions for Seven Contexts

\begin{tabular}{|c|c|c|c|}
\hline & Context & & Descriptions \\
\hline \multirow[b]{2}{*}{1} & \multirow{2}{*}{$\begin{array}{l}\text { Your performance on the } \\
\text { task is dependent on a } \\
\text { computer that you will } \\
\text { use. You are told the } \\
\text { following about the } \\
\text { computer you will use: }\end{array}$} & $\mathrm{C}$ & $\begin{array}{l}\text { The computer you will be working on has } \\
\text { performed well with no technical problems so far. }\end{array}$ \\
\hline & & $\mathrm{U}$ & $\begin{array}{l}\text { The computer you will be working on has } \\
\text { accidentally frozen or shut down once in a while } \\
\text { in the past }\end{array}$ \\
\hline \multirow[t]{2}{*}{2} & \multirow{2}{*}{$\begin{array}{l}\text { Your performance on the } \\
\text { task is dependent on an } \\
\text { alarm that you will use. } \\
\text { You are told the following } \\
\text { about the alarm you will } \\
\text { use: }\end{array}$} & $\mathrm{C}$ & $\begin{array}{l}\text { The alarm on the table has been functioning well } \\
\text { and will go off reliably when the game is } \\
\text { complete. }\end{array}$ \\
\hline & & $\mathrm{U}$ & $\begin{array}{l}\text { The alarm on the table will randomly } \\
\text { go off to indicate the end of the game. }\end{array}$ \\
\hline \multirow[b]{2}{*}{3} & \multirow{2}{*}{$\begin{array}{l}\text { Your performance on the } \\
\text { task is dependent on the } \\
\text { lights in the room that you } \\
\text { will use. You are told the } \\
\text { following about the lights } \\
\text { you will use: }\end{array}$} & $\mathrm{C}$ & $\begin{array}{l}\text { The lights in the room have been functioning } \\
\text { reliably. }\end{array}$ \\
\hline & & $\mathrm{U}$ & $\begin{array}{l}\text { The lights in this room have accidently turned off } \\
\text { every once in a while in the past. }\end{array}$ \\
\hline \multirow[b]{2}{*}{4} & \multirow{2}{*}{$\begin{array}{l}\text { Your performance on the } \\
\text { task is dependent on the } \\
\text { chair in which you will sit. } \\
\text { You are told the following } \\
\text { about the chair in which } \\
\text { you will sit: }\end{array}$} & $\mathrm{C}$ & $\begin{array}{l}\text { hair has recently been replaced with new one } \\
\text { s experiment. }\end{array}$ \\
\hline & & $\mathrm{U}$ & $\begin{array}{l}\text { The chair has been broken so it may collapse at } \\
\text { any time during the experiment. }\end{array}$ \\
\hline \multirow{2}{*}{5} & \multirow{2}{*}{$\begin{array}{l}\text { A research assistant will } \\
\text { be observing your } \\
\text { performance in the room } \\
\text { as a judge. You are told } \\
\text { the following about } \\
\text { the instruction: }\end{array}$} & $\mathrm{C}$ & $\begin{array}{l}\text { The judge tells you that he has been assisting the } \\
\text { experiment for over a semester, so he makes } \\
\text { sure that nothing goes wrong during the game. }\end{array}$ \\
\hline & & $\mathrm{U}$ & $\begin{array}{l}\text { You will be told that the experimenter has just } \\
\text { been hired recently, so he may not be fully used } \\
\text { to the procedure. }\end{array}$ \\
\hline \multirow[b]{2}{*}{6} & \multirow{2}{*}{$\begin{array}{l}\text { You are told the following } \\
\text { about the instructions: }\end{array}$} & $\mathrm{C}$ & $\begin{array}{l}\text { At the beginning of the game the experimenter } \\
\text { ensures that the game will be played for } 20 \text { trials. }\end{array}$ \\
\hline & & $\mathrm{U}$ & $\begin{array}{l}\text { At the beginning of the game the experimenter } \\
\text { reminds you and your partner that you are not } \\
\text { supposed to know how many trials you will } \\
\text { play, and the game might end at any time. }\end{array}$ \\
\hline
\end{tabular}




\begin{tabular}{ll}
\hline $\begin{array}{l}\text { Your performance on the } \\
\text { task is dependent on a } \\
\text { computer that you will }\end{array}$ & $\begin{array}{l}\text { The computer has been replaced with a new one, } \\
\text { so you should not worry about any technical } \\
\text { problems during the experiment. }\end{array}$ \\
\cline { 2 - 2 } $\begin{array}{l}\text { use. You are told the } \\
\text { following about } \\
\text { the computer that you will } \\
\text { use: }\end{array}$ & $\begin{array}{l}\text { While you are filling out the demographics, one of } \\
\text { the computers you or your partner is working } \\
\text { on shuts down. You will be told that the } \\
\text { experimenter does not have a replacement so } \\
\text { you/your partner have to continue to work on the } \\
\text { entire experiment on the same computer. }\end{array}$ \\
\hline $\mathrm{C}=$ Certain, $\mathrm{U}=$ Uncertain &
\end{tabular}

Adjective selection. Ten uncertain adjectives and ten distractor adjectives were generated so that ratings for the certain and uncertain descriptions for each context could be made. To determine adjectives relevant to uncertain feelings, five adjectives (uncertain, surprised, anxious, ambiguous, and fearful) were first drawn based on the Hofstede's operationalization of the uncertainty avoidance dimension (Hofstede, 2001). Next, synonyms of these adjectives were searched in Merriam-Webster Online Dictionary. Among the selected synonyms, adjectives that were included in the Positive and Negative Affect Scale (PANAS; Watson, Clark, \& Tellegen, 1988) were drawn. This procedure yielded another set of five adjectives associated with uncertain feelings (unexpected, unsettled, upset, jittery, and afraid). The selected ten uncertain adjectives corresponded with feelings in the domain of low certainty (Smith \& Ellsworth, 1985), and they were the feelings that most people would find familiar with in everyday life (Watson et al., 1988). To create ten distractor adjectives, adjectives unrelated to uncertain feelings were randomly selected from the PANAS: strong, active, excited, proud, interested, enthusiastic, determined, attentive, inspired, and hostile. These ten uncertain 
adjectives and ten distractor adjectives were randomly ordered in a 9-point Likert scale format.

\section{Participants}

44 students at San Francisco State University were recruited to participate in an online survey in exchange for extra course credit. All of the participants were over 18 years old.

\section{Procedure}

Participants took an online survey via their personal computers (see Appendix A). During the consenting phase, they were told that the purpose of the survey was to investigate people's general moods/feelings to a psychological experiment. During the instruction phase, they were told to imagine that they were a participant in a psychological experiment and performed a task with a partner they just met. The survey consisted of seven sections. Each section began with a brief description about a hypothetical context during a psychological experiment. Then, they were given a certain description followed by an uncertain description. The participants' task was to rate each description separately to what extent each description would evoke the selected 20 feelings, using a 9-point Likert scale $(1=$ Not at all, $5=$ Moderate, $9=$ Extremely). They repeated the same procedure for the seven contexts. The order of contexts was randomized across the participants.

\section{Results}


The purpose of Study 1 was to determine uncertain contexts that would be used to manipulate uncertainty in Study 2. Selecting three most uncertain contexts from the current analysis was most appropriate, because three descriptions would concisely fit within a single screen shot which would be displayed on a computer screen during the game in Study 2.

To determine top three uncertain contexts, we set up three criteria. The first criterion was whether all of the scores of uncertain adjectives in the uncertain descriptions were higher than in the certain descriptions. The second criterion was whether aggregated scores of uncertain adjectives in the uncertain descriptions were significantly higher than the certain descriptions. The third criterion was whether aggregated scores of distractor adjectives in the uncertain descriptions were not significantly different from in the certain descriptions.

Criterion 1. Scores on each ten uncertain adjective served as a dependent variable in this analysis. Dependent $t$-tests were performed on the scores of uncertain adjectives between the uncertain descriptions and the certain descriptions within each context (Table 3). The data showed that only Context 2 met this criterion. Context 3, 4, and 7 had similar patterns except for ambiguous being not significantly different. 
Table 3

Mean Differences on Uncertain Adjectives between Uncertain Descriptions and Certain Descriptions

\begin{tabular}{cccccccc}
\hline & \multicolumn{7}{c}{ Contexts } \\
\cline { 2 - 8 } & 1 & 2 & 3 & 4 & 5 & 6 & 7 \\
\hline Uncertain & $3.38^{* *}$ & $2.64^{* *}$ & $2.82^{* *}$ & $3.53^{* *}$ & $1.85^{* *}$ & $2.19^{* *}$ & $2.78^{* *}$ \\
Anxious & $2.70^{* *}$ & $1.75^{* *}$ & $2.39^{* *}$ & $3.50^{* *}$ & .74 & $1.46^{* *}$ & $1.97^{* *}$ \\
Scared & $2.35^{* *}$ & $1.33^{* *}$ & $2.08^{* *}$ & $3.472^{* *}$ & .85 & $1.32^{* *}$ & $1.67^{* *}$ \\
Ambiguous & .62 & $1.00^{*}$ & .74 & .72 & .71 & $1.54^{* *}$ & .58 \\
Unexpected & 2.59 & $2.92^{* *}$ & $3.29^{* *}$ & $3.19^{* *}$ & $1.65^{* *}$ & $2.08^{* *}$ & $3.64^{* *}$ \\
Surprised & $1.27^{* *}$ & $2.08^{* *}$ & $2.50^{* *}$ & $2.94^{* *}$ & 1.03 & $1.49^{* *}$ & $2.72^{* *}$ \\
Afraid & $2.73^{* *}$ & $1.81^{* *}$ & $2.08^{* *}$ & $3.86^{* *}$ & $1.15^{* *}$ & $1.49^{* *}$ & $1.78^{* *}$ \\
Upset & $2.46^{* *}$ & $1.33^{* *}$ & $1.92^{* *}$ & $3.36^{* *}$ & .71 & .62 & $3.39^{* *}$ \\
Unsettled & $2.95^{* *}$ & $2.39^{* *}$ & $3.08^{* *}$ & $3.69^{* *}$ & $1.65^{* *}$ & $1.73^{* *}$ & $3.03^{* *}$ \\
Jittery & $1.46^{* *}$ & $1.64^{* *}$ & $1.74^{* *}$ & $2.78^{* *}$ & .79 & $1.11^{* *}$ & $1.47^{* *}$ \\
\hline$* *$
\end{tabular}

${ }^{* *} p<.01,{ }^{*} p<.05$. Positive number indicates greater uncertain feelings in uncertain description than in certain description.

Criterion 2. Aggregated scores of the uncertain adjectives served as a dependent variable in this analysis. Dependent $t$-tests were performed on the aggregated scores of the uncertain adjectives between the uncertain descriptions and the certain descriptions within each context. All of the uncertain descriptions had higher aggregated scores of the uncertain adjectives than did the certain descriptions (Table 4). The result suggested that Context 4,1 , and 3 , were the three most uncertain contexts in the order of the effect size, from $d=1.35, d=1.27$, to $d=1.27$, respectively. 
Table 4

Mean Differences on Aggregated Scores of Uncertain Adjectives between Uncertain Descriptions and Certain Descriptions

\begin{tabular}{|c|c|c|c|c|c|c|c|}
\hline Context & $N$ & $d f$ & $\begin{array}{c}\text { Mean } \\
\text { Difference }\end{array}$ & $S D$ & $S E$ & $t$ & $d$ \\
\hline 1 & 38 & 37 & $22.00 * *$ & 17.31 & 2.81 & 7.83 & 1.27 \\
\hline 2 & 40 & 39 & $18.90 * *$ & 19.96 & 3.16 & 5.99 & .95 \\
\hline 3 & 39 & 38 & $22.38 * *$ & 17.58 & 2.82 & 7.95 & 1.27 \\
\hline 4 & 38 & 37 & $31.05^{* *} *$ & 22.95 & 3.72 & 8.34 & 1.35 \\
\hline 5 & 37 & 36 & $11.62 * *$ & 20.24 & 3.32 & 3.49 & .57 \\
\hline 6 & 39 & 36 & $15.13 * *$ & 16.63 & 2.66 & 5.68 & .91 \\
\hline 7 & 36 & 35 & $23.03 * *$ & 20.84 & 3.47 & 6.63 & 1.11 \\
\hline
\end{tabular}

Criterion 3. Aggregated scores of the distractor adjectives served as a dependent variable in this analysis. Dependent $t$-tests were performed on the aggregated scores of the distractor adjectives between the uncertain description and the certain descriptions within each context. The result showed that there were no significant differences on the aggregated scores of the distractor adjectives between uncertain descriptions and neutral descriptions for Context 1, 3, 4, 5, and 6 (Table 5). 
Table 5

Mean Differences on Aggregated Non-Uncertainty Scores between Uncertain Description and Certain Descriptions

\begin{tabular}{cccccccc}
\hline Context & $N$ & $d f$ & $\begin{array}{c}\text { Mean } \\
\text { Difference }\end{array}$ & $S D$ & $S E$ & $t$ & $d$ \\
\hline 1 & 38 & 37 & -4.24 & 14.12 & 2.29 & -1.85 & .3 \\
2 & 37 & 36 & $12.97^{* *}$ & 16.75 & 2.75 & 4.71 & .77 \\
3 & 38 & 37 & -3.55 & 13.53 & 2.19 & -1.62 & .26 \\
4 & 38 & 37 & -.50 & 11.49 & 1.86 & -.27 & .04 \\
5 & 37 & 36 & -3.30 & 12.43 & 2.04 & -1.61 & .26 \\
6 & 38 & 37 & 2.79 & 11.28 & 1.83 & 1.53 & .25 \\
7 & 38 & 37 & $-6.13 *$ & 16.54 & 2.68 & -2.29 & .37 \\
\hline
\end{tabular}

${ }^{* *} p<.01,{ }^{*} p<.05$. Positive numbers indicate greater distractor feelings in uncertain description than in certain description.

\section{Discussion}

Only Context 2 met the criterion 1. Analysis for the criterion 2 suggested all of the contexts would elicit higher uncertain feelings in the uncertain descriptions than in the certain descriptions. Analysis for the criterion 3 suggested that Context 2 and 7 would evoke distractor feelings that may disrupt the effects of uncertain feelings. Thus, although Context 2 met the criterion 1 and 2, it was eliminated from the final selection. Following all of the criteria, five contexts remained: Context $1,3,4,5$, and 6 . The final selection of the three most uncertain contexts among the five candidates were determined based on the effect size in the analysis of the criterion 2 . This procedure resulted in the Context 1 , 3, and 4. Uncertain descriptions in these contexts would expectedly elicit uncertain 
feelings, with minimal effects of the distractor feelings, compared to the certain descriptions. These descriptions were embedded as contextual manipulations with minor modifications in the experiment in Study 2.

\section{Study 2}

\section{Method}

The purpose of Study 2 was to demonstrate that uncertainty avoidance as a contextual-level variable would account for Japan-U.S. differences in cooperative behaviors. Individual-level variables of IC values, neuroticism, and intolerance of uncertainty were measured as potential mediators and covariates of the contextual effects and Japan-U.S. group differences on cooperative behaviors.

\section{Experimental design}

There were two manipulations in the current experiment. First, the level of certainty was manipulated; participants were randomly placed into either a certainty (control) or uncertainty (experimental) condition during the ultimatum game. In the certainty condition, participants were given descriptions about the laboratory room in which they were to participate in the experiment which indicated a stable, certain environment. In the uncertainty condition, participants were given descriptions which indicated instability and uncertainty. Those descriptions were drawn from Study 1 with minor modifications to appear more natural in the context of the current experiment. Second, the role order in the ultimatum game was manipulated. That is, half the 
participants were randomly assigned to play a proposer in the first trial, and the other half were assigned to play a responder in the first trial. The roles were switched in the second trial. Country group (U.S./Japan) served as a quasi-experimental variable. Therefore, the current study was conducted as a 2 (Context) x 2 (Role Order) x 2 (Country) betweensubjects design.

\section{Participants}

The U.S. group consisted of 70 students recruited via an institutional psychology research participation system (SONA) in exchange for both course credits and monetary compensation. Nine participants were excluded from data analysis because they were not born and raised in the U.S. and did not speak English as a native language. Thus, U.S. participants consisted of 61 individuals $($ Male $=13$, Female $=46$, Unspecified $=2$, . Of the remaining participants, $17(27.8 \%)$ identified non-English languages as their first languages, but they were included in Japan-U.S. country comparison since they were born and raised in the U.S. and simultaneously learned English as a native language. Of the participants who had lived outside of English-speaking North America (8\%), the average year of living was $6.20(S D=7.27)$.

The Japanese group consisted of 60 international students from Japan (Male $=28$, Female $=32$ ), all of whom spoke Japanese as their native language. The Japanese participants were a convenience sample of students, recruited directly on campus at San Francisco State University through direct contact. The majority of them $(81.67 \%)$ 
identified English as their second language. Participants in this group, on average, had spent 2.31 years $(S D=2.58)$ living in English-speaking countries.

An independent $t$-test was run to test age differences between the U.S. and Japanese participants and produced a marginal difference, such that U.S. participants were relatively older $(M=23.55, S D=6.02)$ than were Japanese participants $(M=22, S D$ $=2.44), t(118)=1.85, p=.07, d=.34$. An independent $t$-test was performed on the difference in the years of living in outside of their native countries between the U.S. participants and Japanese participants. The analysis revealed that the Japanese participants spent more years $(M=2.31, S D=2.58)$ than did the U.S. participants $(M=$ $.52, S D=2.56)$ living outside of their country of origin, $t(119)=-3.82, p<.001, d=-.70$.

Participants were recruited on campus via an advertisement which offered them anywhere from $\$ 0$ to $\$ 10$ dollars, depending on their performance in a decision-making game. This was necessary to ensure that participants, when in the study, had incentive to perform; in reality, to ensure that they were all compensated fairly for their time, all participants were awarded $\$ 5$ at the completion of the study, regardless of performance. Overall 121 participants (U.S. $=61, \mathrm{JP}=60$ ) were included in the current U.S.-Japan analysis (see Table 6 for other relevant participant characteristics). 
Table 6

Participant Characteristics

\begin{tabular}{|c|c|c|}
\hline & US & JP \\
\hline $\mathrm{N}$ & 61 & 60 \\
\hline \multicolumn{3}{|l|}{ Gender } \\
\hline Male & $13(21.3 \%)$ & $28(46.7 \%)$ \\
\hline Female & $46(75.4 \%)$ & $32(53.3 \%)$ \\
\hline Other & $2(3.3 \%)$ & $0(0 \%)$ \\
\hline \multicolumn{3}{|l|}{ Ethnicity } \\
\hline Caucasian & $21(35 \%)$ & $0(0 \%)$ \\
\hline African & $3(5 \%)$ & $0(0 \%)$ \\
\hline Hispanic/Latino & $15(25 \%)$ & $0(0 \%)$ \\
\hline Asian & $16(26.7 \%)$ & $59(98.3 \%)$ \\
\hline Others & $5(8.3 \%)$ & $1(1.7 \%)$ \\
\hline \multicolumn{3}{|l|}{ Religion } \\
\hline Non-Religious & $22(36.1 \%)$ & $49(81.7 \%)$ \\
\hline Catholic/Christian & $19(31.1 \%)$ & $2(3.3 \%)$ \\
\hline Buddhism & $1(1.6 \%)$ & $7(11.7 \%)$ \\
\hline Other & $19(31.1 \%)$ & $2(3.3 \%)$ \\
\hline
\end{tabular}

Note. Numbers indicate raw numbers of participants.

\section{Materials}

\section{Self-reported measures}

HVIC. The Horizontal-Vertical Individualism/Collectivism scale (HVIC scale:

Singelis et al., 1995; Triandis, 1995; Triandis \& Gelfand, 1998) was used to assess IC values. The scale is composed of four subscales: Horizontal-Collectivism (HC: 8 items), Vertical-Collectivism (VC: 8 items), Horizontal-Individualism (HI: 8 items), and Vertical-Individualism (VI: 8 items). Alphas obtained for the U.S. and Japanese samples 
were as follows: $\mathrm{HC}(\alpha=.59, .35), \mathrm{VC}(\alpha=.71, .69), \mathrm{HI}(\alpha=.62, .57)$, and $\mathrm{VI}(\alpha=.69$, 66), respectively.

Intolerance of uncertainty. The Intolerance of Uncertainty Scale (IUS; Buhr \& Dugas, 2002; Freeston, Rhe'aume, Letarte, Dugas, \& Ladouceur, 1994) was used to assess intolerance of uncertainty. The IUS contained 27 items and was translated into Japanese with a back-translation procedure. Alphas for the U.S. and the Japanese samples in the current study were acceptable, $\alpha=.93$ and .89 , respectively.

Neuroticism. Items of the N-domain of NEO-FFI-3 (Costa \& McCrae, 1992) were used to assess neuroticism. The $\mathrm{N}$-domain contained 12 items measuring one's general tendency to feel negative moods such as anxiety, stress, and anger. Alphas for the U.S. and the Japanese samples in the current study were acceptable, $\alpha=.83$ and .76 , respectively.

Adjective checklist. The adjective checklist created in Study 1 was used as a manipulation check. After finishing the UG, participants were presented with a series of twenty adjectives and asked to indicate on a 9 point Likert scale $(1=$ not at all, $5=$ moderate, 9 = extremely) the degree to which they felt each emotion-related adjective. Ten of the adjectives were taken from the Study 1 checklist and were related to uncertainty. These were embedded in a list of 10 other adjectives which were selected as distractor words. Alphas for the U.S. and the Japanese samples on the uncertainty adjectives were acceptable, $\alpha=.88$ and .84 , respectively. 


\section{Experimental measures}

The Ultimatum Game. The experiment was programmed and conducted with the experiment software z-Tree (Fischbacher, 2007). In the current study, \$5 was distributed to a proposer in each trial. An anonymous partner played by an automated computer was programmed to offer $\$ 1$ as a proposer and to accept the participants' offers as a responder.

\section{Procedure}

Participants completed each task in the experiment independently and in isolation; in between tasks, an experimenter who was fluent in English and Japanese interacted with participants in order to answer questions if they had any. Once they indicated that they knew how to proceed, the experimenter once again left the room. The conditions to which participants would be assigned were determined by the experimenter using random assignment before their arrivals.

Upon arrival at the laboratory room, participants were greeted and seated by the experimenter at a table in the middle of the room. During the informed consent phase, participants were given brief instructions about the UG, which emphasized that they would play "a bargaining game with a partner in a separate room," via a computer and that they would receive monetary compensation ranging from $\$ 0$ to $\$ 10$, depending on their performance in the game (see Appendix B). 
After consenting to participate, participants were given a hard copy consisting of three questionnaires to complete; the HVIC, IUS, and the N-domain of the NEO-FFI (see Appendix C). The order in which the scales were presented was randomized across participants.

After completing the questionnaires, participants were seated in a different chair in front of a computer to play the UG: They were first instructed to press the "Start" button on the screen to begin the instruction, then were presented with the instructions for the current version of the UG, followed by an exemplary scenario. At the end of the instructions, they were reminded that the total amount of monetary compensation would depend on how they performed during the two trials. Before the first trial began, participants were randomly placed into either uncertain/certain context. Participants assigned to the certainty condition were presented with the following scripts:

Additional Information about the Experimental Room Before we begin the game, university policy requires us to inform you of the following information regarding equipment: The computer you are using has performed well with no technical problems so far. The lights in the room have been functioning reliably. The chair on which you are sitting has recently been replaced with a new one for this experiment. 
Participants assigned to the uncertainty condition were presented with the following script:

\section{Additional Information about the Experimental Room}

Before we begin the game, university policy requires us to inform you of the following information regarding equipment: The computer you are using has accidentally frozen or shut down once in a while in the past. The lights in this room have accidently turned off every once in a while in the past. The chair on which you are sitting has been broken. We've tried our best to fix it, but it may collapse at any time during the game.

After the manipulation, participants played the first trial of the UG on a computer screen with another partner (an automated computer). Participants assigned to be the proposer in the first trial were given $\$ 5$ and were asked to type in how much money they wanted to keep to themselves; they were allowed to choose any amount between $\$ 0$ and $\$ 5$, and were told that the remainder of the money would be offered to responder. After the decision a display appeared, informing the proposer that the responder was making a decision (the display was programmed to last for ten seconds). Then, a new display appeared with the responder's decision and the total outcomes earned between the two players in the first trial. After the resulting display, the proposer was told to be a responder in the next trial. After the proposer's decision (also programmed to last for ten 
seconds), the screen displayed the amount of offer the proposer gave to the responder: $\$ 1$. The responder was asked to indicate whether to accept or reject the offer by clicking the appropriate button. After the responder's decision, the screen displayed the total outcomes earned between the two players in the second trial, followed by the total outcomes both players earned from the two trials. Afterwards, participants were instructed to ring a bell on the table to call the experimenter for the next phase of the study. Participants assigned to be a responder in the first trial followed the exact same procedures (see Appendix D).

After finishing the UG, the participants were seated back at the original table and asked to complete a paper questionnaire consisting of a manipulation check and demographic questions (Appendix E). After completing the follow-up questionnaire, participants were debriefed and handed $\$ 5$ in cash, no matter how they played during the UG. During the debriefing (Appendix F), they were asked whether they knew beforehand that their monetary compensations were independent of their actual performances during the UG. 


\section{Results}

Manipulation check. To test the prediction that participants in the uncertainty condition felt greater uncertainty than those in the certainty condition, independent $t$-tests were performed for reported feelings on each adjective on the adjective checklist, comparing the certainty condition with the uncertainty condition. None of the differences between conditions reached the .05 level of statistical significance (see Table 7).

Table 7

Reported Feelings on Each Adjective between Uncertain Context and Uncertain Context

\begin{tabular}{ccccccc}
\hline \multirow{2}{*}{ Adjective } & \multicolumn{2}{c}{ Context } & & & & \\
\cline { 2 - 3 } & Certain & Uncertain & $t$ & $d f$ & $p$ & $d$ \\
\hline Uncertain & $4.13(2.76)$ & $4.75(2.49)$ & -1.30 & 119 & .19 & -.24 \\
Anxious & $3.13(2.52)$ & $3.39(2.64)$ & -.55 & 119 & .58 & -.10 \\
Scared & $2.05(1.94)$ & $2.15(1.86)$ & -.28 & 119 & .78 & -.05 \\
Ambiguous & $3.86(2.55)$ & $3.72(2.47)$ & .31 & 118 & .76 & .06 \\
Unexpected & $4.72(2.68)$ & $4.72(2.60)$ & -.01 & 119 & .99 & -.00 \\
Surprised & $4.35(2.67)$ & $4.49(2.81)$ & -.28 & 119 & .78 & -.05 \\
Afraid & $2.28(1.92)$ & $2.45(2.22)$ & -.44 & 118 & .66 & -.08 \\
Upset & $2.47(2.17)$ & $2.88(2.43)$ & -.99 & 118 & .32 & -.18 \\
Unsettled & $3.15(2.35)$ & $3.17(2.36)$ & -.04 & 118 & .97 & -.01 \\
Jittery & $2.47(2.08)$ & $2.51(2.21)$ & -.09 & 118 & .93 & -.02 \\
Inspired & $3.23(2.50)$ & $3.75(2.33)$ & -1.19 & 119 & .24 & -.22 \\
Hostile & $2.67(2.32)$ & $2.64(2.33)$ & .07 & 119 & .95 & -.01 \\
Strong & $3.00(2.33)$ & $3.25(2.23)$ & -.61 & 117 & .55 & -.11 \\
Active & $3.67(2.48)$ & $3.64(2.71)$ & .06 & 119 & .95 & .01 \\
Excited & $4.22(2.64)$ & $3.82(2.62)$ & .83 & 119 & .41 & .15 \\
Proud & $3.43(2.47)$ & $3.13(2.29)$ & .70 & 119 & .49 & .13 \\
Interested & $6.30(2.36)$ & $6.18(2.52)$ & .27 & 119 & .79 & .05 \\
Enthusiastic & $5.03(2.83)$ & $4.39(2.84)$ & 1.24 & 119 & .22 & .23 \\
Determined & $3.92(2.76)$ & $3.52(2.64)$ & .80 & 119 & .43 & .15 \\
Attentive & $5.73(2.74)$ & $5.52(2.63)$ & .43 & 119 & .67 & .08 \\
\hline
\end{tabular}

Note. Standard deviations appear in parentheses. $d=$ Cohen's $d$ 
In addition, a 2 (Country) x 2 (Context) between-subject factorial ANOVA was performed on the overall scores of reported uncertainty after the ultimatum game in order to test the predicted effect of the uncertainty manipulation (descriptive statistics for both uncertainty and distractors are provided in Table 8). There was no significant main effect of Context, $F(1,117)=.29, p=.59, \eta^{2}=.00$, indicating that participants did not feel higher uncertainty in the uncertainty condition $(M=3.41, S D=1.52)$ than in the certainty condition $(M=3.25, S D=1.69)$. There was no significant two-way interaction effect of Country x Condition, $F(1,117)=.09, p=.77, \eta^{2}=.00$. (see Figure 1$)$. There was a significant main effect of Country, $F(1,117)=11.72, p<.01, \eta^{2}=.09$, indicating that the U.S. participants rated themselves higher $(M=3.81, S D=1.75)$ than did the Japanese $(M$ $=2.85, S D=1.28)$, regardless of the type of feeling.

The analyses above suggested that the participants in the uncertainty condition did not feel greater uncertainty than did those in the certainty condition. Moreover, the significant main effect of country indicated that the U.S. participants gave higher ratings than did the Japanese regardless of the type of feeling and context.

Table 8

Descriptive Statistics for Overall Reported Feelings on the Adjective Checklist

\begin{tabular}{cccc}
\hline \multirow{2}{*}{ Country } & \multirow{2}{*}{ Context } & \multicolumn{2}{c}{ Type of adjectives } \\
\cline { 2 - 4 } & Certain & $4.33(1.86)$ & $3.77(1.89)$ \\
\multirow{2}{*}{ US } & Uncertain & $4.30(1.60)$ & $3.84(1.62)$ \\
\multirow{2}{*}{ JP } & Certain & $3.91(1.46)$ & $2.73(1.29)$ \\
& Uncertain & $3.64(1.72)$ & $3.41(1.52)$ \\
\hline
\end{tabular}

Note. Standard Deviations appear in parentheses below means. 


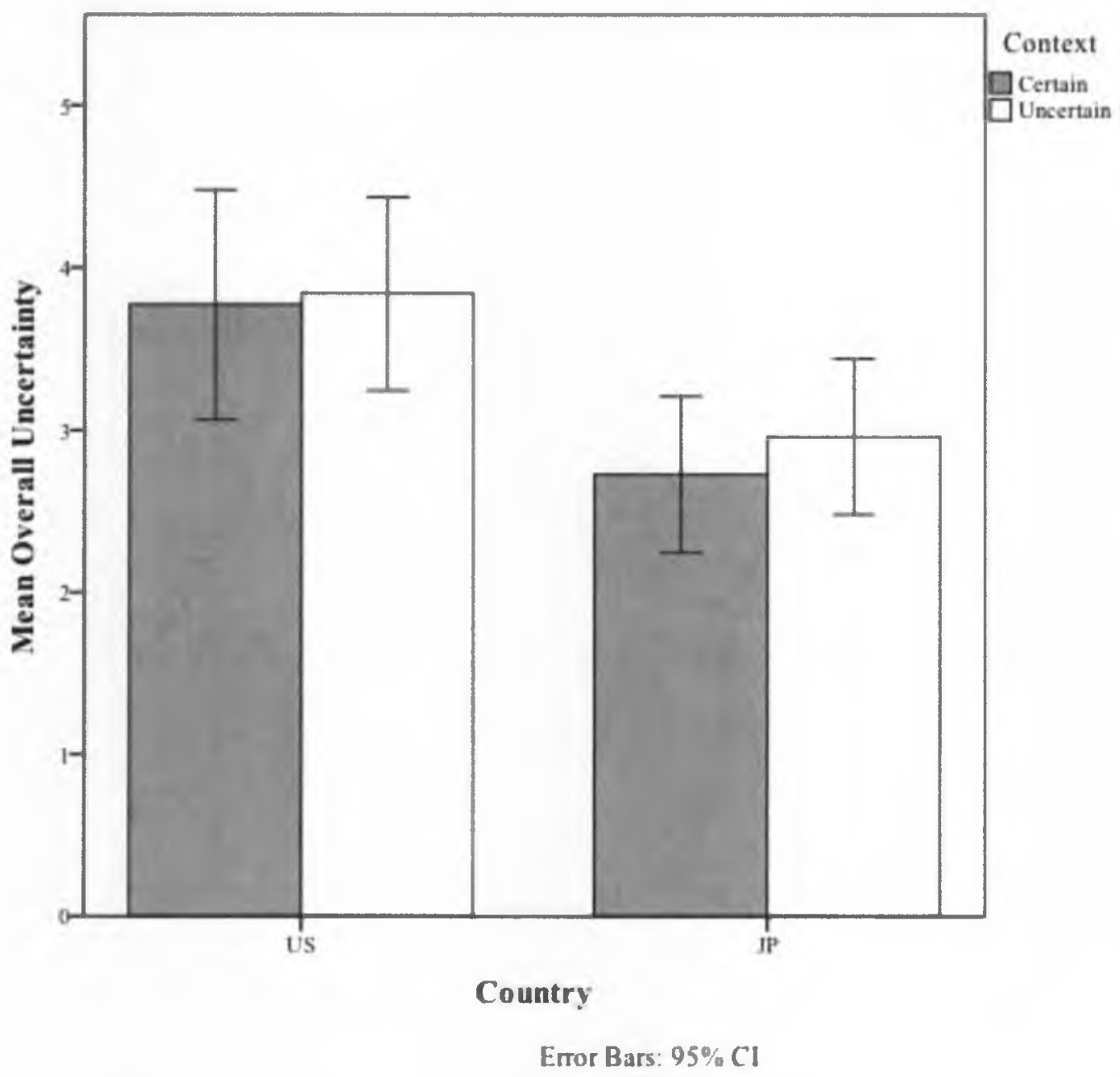

Figure 1. Overall self-reported uncertainty between the certain condition and the uncertain condition. Error bars represent standard errors.

\section{Individual-level analysis}

The individual-level analysis tested the following five hypotheses.

Hypothesis 1: Japanese would score higher on neuroticism than Americans. 
Hypothesis 2: Japanese would score higher on intolerance of uncertainty than Americans.

Hypothesis 3: Americans would score higher on individualistic values than Japanese when uniqueness is included as an attribute of individualism (horizontalindividualism).

Hypothesis 4: Japanese would score higher on individualistic values than Americans when uniqueness is removed as an attribute of individualism (vertical individualism).

Hypothesis 5: Americans would score higher overall on collectivistic values than Japanese.

Neuroticism. To test Hypothesis 1, an independent $t$-test was performed on the aggregated scores of neuroticism between the Americans and Japanese. There was no significant difference on neuroticism between the U.S. participants $(M=2.00, S D=.70)$ and Japanese participants $(M=2.10, S D=.61), t(119)=-.85, p=.400, d=.15$. Thus, Hypothesis 1 was not supported.

Intolerance of Uncertainty. To test Hypothesis 2, an independent $t$-test was performed on the aggregated scores of intolerance of uncertainty between Americans and Japanese. As predicted, the Japanese showed higher intolerance of uncertainty $(M=2.75$, 
$S D=.60)$ than did the U.S. counterparts $(M=2.41, S D=.71), t(119)=-2.90, p=.004, d$ $=.52$. Therefore, the hypothesis 2 was supported.

IC Values. To test Hypotheses 3, 4, and 5, a 2 (Country) x 2 (IC:

Individualism/Collectivism) x 2 (VH: Vertical/Horizontal) mixed-factorial ANOVA with country as a between-subjects variable was performed. There was a significant three-way interaction of Country x IC x HV, $F(1,119)=48.64, p=.001, \eta^{2}=.29$ (see Table 9). Post hoc analyses revealed that the U.S. participants scored higher on horizontalindividualism scores $(M=7.19, S D=.95)$ than did the Japanese participants $(M=6.30$, $S D=.99), t(119)=5.02, p=.001, d=.92$, indicating that Hypothesis 3 was supported. Additionally, the Japanese participants had higher vertical-individualism scores $(M=$ $5.58, S D=1.27)$ than did the U.S. participants, $(M=4.59, S D=1.32), t(119)=-4.19, p=$ $.001, d=-.77$, indicating that Hypothesis 4 was supported. The U.S. participants showed marginally higher levels of vertical-collectivism $(M=5.23, S D=1.30)$ than did the Japanese $(M=4.83, S D=1.23), t(119)=1.74, p=.08, d=.32$. There was no difference between the U.S. participants and the Japanese participants on horizontal-collectivism scores, $t(119)=.99, p=.32, d=.18$. 
Table 9

Three-Way Interaction of Country $x \mathrm{I} / \mathrm{C} \times \mathrm{H} / \mathrm{V}$

\begin{tabular}{|c|c|c|c|c|c|c|c|}
\hline \multicolumn{4}{|c|}{ Individualism } & & \multicolumn{3}{|c|}{ Collectivism } \\
\hline & $\mathrm{H}$ & V & Overall & & $\mathrm{H}$ & V & Overall \\
\hline US & $\begin{array}{l}7.19 \\
(.95)\end{array}$ & $\begin{array}{c}4.59 \\
(1.32)\end{array}$ & $\begin{array}{l}5.89 \\
(.83)\end{array}$ & US & $\begin{array}{l}6.71 \\
(.91)\end{array}$ & $\begin{array}{c}5.23 \\
(1.30)\end{array}$ & $\begin{array}{l}5.97 \\
(.97)\end{array}$ \\
\hline JP & $\begin{array}{l}6.30 \\
(.99)\end{array}$ & $\begin{array}{c}5.58 \\
(1.27)\end{array}$ & $\begin{array}{l}5.94 \\
(.91)\end{array}$ & JP & $\begin{array}{l}6.56 \\
(.74)\end{array}$ & $\begin{array}{c}4.83 \\
(1.23)\end{array}$ & $\begin{array}{l}5.69 \\
(.78)\end{array}$ \\
\hline$d$ & $.92 * *$ & $-.77 * *$ & -.06 & $d$ & .18 & .32 & .32 \\
\hline
\end{tabular}

Note. $\mathrm{H}=$ Horizontal, $\mathrm{V}=$ Vertical, $d=$ Cohen's $d$. Standard deviations are shown in parenthesis. $* *=p<.01$.

The two-way interaction of Country $\mathrm{x}$ IC was not significant, $F(1,119)=2.42, p$ $=.12, \eta^{2}=.02$. A contrast test on the individualism dimension revealed that the U.S. participants $(M=5.89, S D=.83)$ did not differ from the Japanese participants $(M=5.94$, $S D=.91)$ on their overall individualism score, $t(119)=-.32, p=.75, d=-.06$. A contrast on the collectivism dimension revealed that the U.S. participants showed marginally higher overall levels of collectivism $(M=5.97, S D=.97)$ than did the Japanese participants $(M=5.69, S D=.78), t(119)=1.72, p=.09, d=.32$. Thus, Hypothesis 5 was partially supported.

Overall, the non-significant two-way interaction of Country $\mathrm{x}$ IC indicated that a single dimension of individualism and collectivism did not produce a clear-cut JapanU.S. difference as traditionally assumed. A marginal country difference on collectivism was observed, indicating that the Americans were slightly more collectivistic than the 
Japanese. As predicted for the individualism dimension, the Americans perceived themselves as unique more than the Japanese, whereas the Japanese were more accepting of inequality and competition than the Americans.

Relationships between individual-level attributes. Zero-order correlations of all individual-level attributes were computed (see Table 10). Several factors correlated positively with the intolerance of uncertainty. Namely, neuroticism had the highest correlation with intolerance of uncertainty, indicating that individuals with a greater disposition towards neuroticism were more likely to report intolerance of uncertainty. This resembled Hofstede \& McCrae's (2004) earlier finding on the country-level association between neuroticism and uncertainty avoidance. Vertical-individualism and vertical-collectivism correlated positively with the intolerance of uncertainty. Taken together, this suggested that those who valued hierarchy more favorably were more likely to have negative perceptions toward uncertainty.

In addition, vertical-collectivism correlated positively with horizontalcollectivism, as these variables were in the collectivistic dimension. On the other hand, vertical-individualism and horizontal-individualism were not correlated, indicating that these two variables, though both included in the individualism dimension, were independent of each other. 
Table 10

Zero-Order Correlations between Individual-Level Variables

\begin{tabular}{ccccccc}
\hline & H-I & V-I & H-C & V-C & N & IU \\
\hline H-I & - & & & & & \\
V-I & -.01 & - & & & & \\
H-C & .15 & -.15 & - & & & \\
V-C & .16 & .12 & $.39 * *$ & - & & \\
N & -.07 & .16 & -.05 & .16 & - & \\
IU & -.05 & $.33^{* *}$ & .03 & $.32^{* *}$ & $.63^{* *}$ & - \\
\hline
\end{tabular}

Note. ${ }^{* *}=$ significant at $p<.01 . \mathrm{H}-\mathrm{I}=$ horizontal-individualism, $\mathrm{V}-\mathrm{I}=$ verticalindividualism, $\mathrm{H}-\mathrm{C}=$ horizontal-collectivism, $\mathrm{V}-\mathrm{C}=$ vertical-collectivism, $\mathrm{N}=$ neuroticism, IU $=$ intolerance of uncertainty.

\section{Experimental analyses}

The experimental analysis tested the following two hypotheses:

Hypothesis 6: Individuals primed with uncertainty in the ultimatum game would show greater cooperative behaviors than those not primed with uncertainty.

Hypothesis 7: Japanese primed with uncertainty would cooperate more than Americans primed with uncertainty.

\section{Cooperative behavior 1 - the amount of money participants proposed during}

the ultimatum game. To test Hypotheses 6 and 7, a 2 (Country) x 2 (Context) x 2 (Game Order) between-subject factorial ANOVA was performed on the amount of money the participants proposed as a proposer during the ultimatum game. There was a marginal 
main effect of Context, $F(1,113)=3.64, p=.06, \eta^{2}=.03$, indicating that participants in the uncertainty context proposed more money to the partner $(M=2.30, S D=1.01)$ than did those in the certainty context $(M=2.00, S D=.83)$. The main effect of Country was not significant, $F(1,113)=.02, p=.90, \eta^{2}=.00$. The two-way interaction of Country $\mathrm{x}$ Context was not significant, $F(1,113)=1.03, p=.31, \eta^{2}=.01$ (see Figure 2). The three way interaction of Country $\mathrm{x}$ Context $\mathrm{x}$ Game order was not significant, $F(1,113)=.74$, $p=.39, \eta^{2}=.01$. There was a significant main effect of Game Order, $F(1,113)=12.90$, $p=.001, \eta^{2}=.10$, indicating that participants who played a proposer first proposed more money $(M=2.45, S D=.93)$ than did those who played a responder first $(M=1.86, S D=$ .86), suggesting that the participants who were first given an unfair offer by the partner tended to propose a lower amount of money in the following round. 


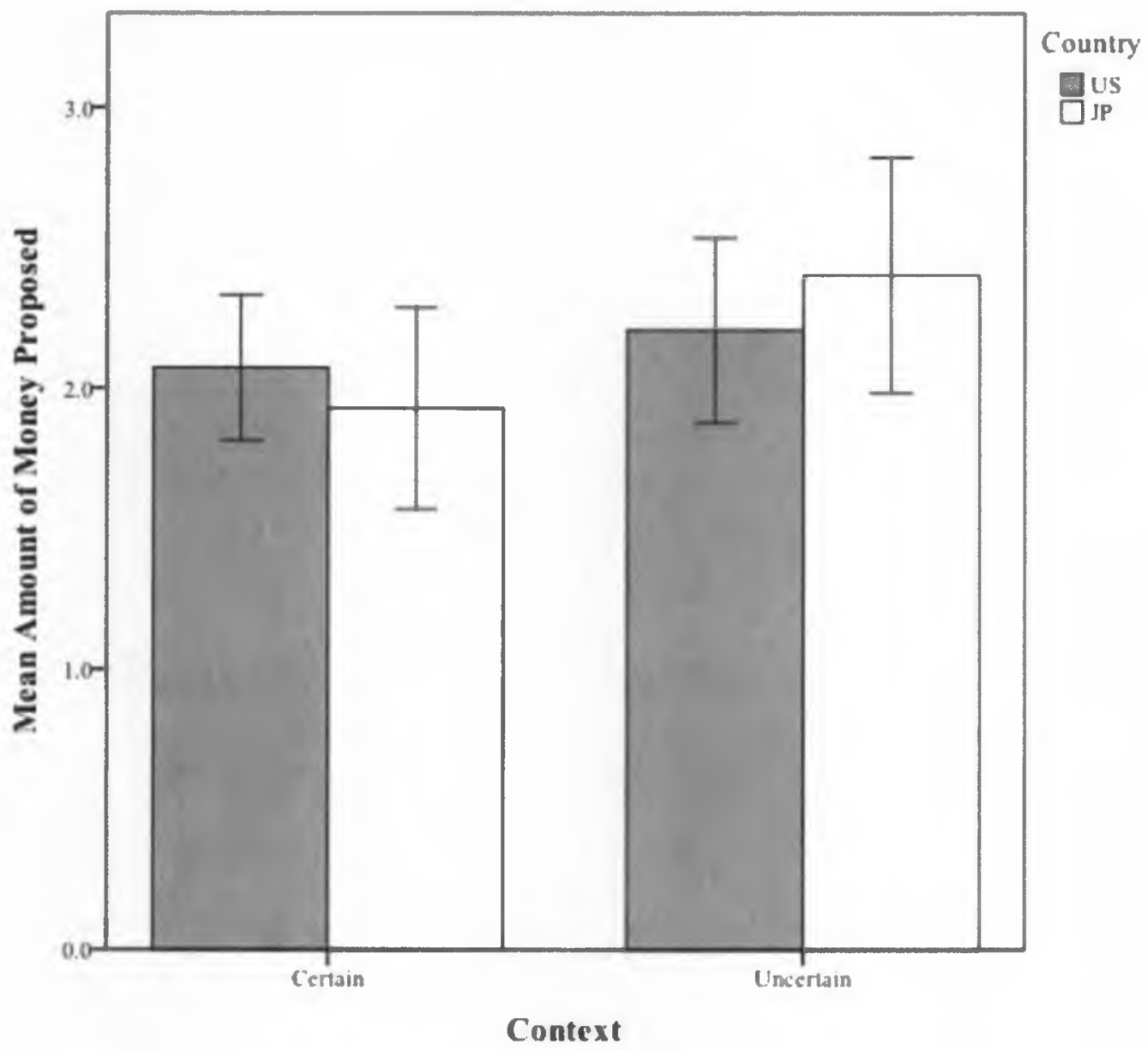

Error Bars: $95 \% \mathrm{Cl}$

Figure 2. The two-way interaction of Country and Context on the amount of money participants proposed to another partner during the ultimatum game. Error bars represent standard errors.

Since there were no significant country differences on the cooperative behavior, mediation analysis was not performed. Instead, individual differences were included as covariates on the effect of context on the dependent variable. After controlling for levels of overall individualism, which negatively correlated with the amount of money the participants proposed at a marginal significance level, $r=-.15, p=.10$, the main effect of 
Context on the amount of money the participants proposed was still significant, $F(1,112)$ $=4.31, p=.04, \eta^{2}=.04$. With the intolerance of uncertainty as a covariate, the main effect of Context on the dependent variable was still marginally significant, $F(1,112)=$ $3.47, p=.07, \eta^{2}=.03$. No other individual-level variables significantly correlated with the two types of dependent variables.

The data partially supported hypothesis 6 , indicating that there was a consistent effect of uncertain context on cooperative behavior, regardless of country, individuallevel IC, and intolerance of uncertainty. However, there was no significant country difference on the cooperative behavior, nor a significant two-way interaction of Context $\mathrm{x}$ Country. Hypothesis 7 was not supported.

\section{Cooperative behavior 2 - participants' choice as a responder during the}

ultimatum game. Participants' choice regarding whether to accept or reject an unfair offer by another partner during the ultimatum game served as another index of cooperative behavior (descriptive statistics on the participants' choices are provided in Table 11 and Figure 3). To test Hypotheses 6 and 7 using this dependent variable, a fourway log-linear analysis (Country x Context x Game Order x Choice) was conducted with a backward elimination procedure. Backward elimination was appropriate since there was no a priori hypothesis regarding this dependent variable. The analysis produced a final model that retained the interaction effects of Context $\mathrm{x}$ Choice and Game Order $\mathrm{x}$ Choice, but the significance level was negligent, $\chi^{2}(10)=1.57, p=.99$. Therefore, country, game 
order, and context did not affect participants' choices as responder. There was a significant partial effect of Choice, $\chi^{2}(1)=39.28, p=.001$, suggesting that participants were more likely to accept the partner's offer $(77.7 \%)$ than reject $(22.3 \%)$. Hypotheses 6 and 7 were not supported.

Table 11

Descriptive Statistics on Participants' Choice as a Responder during the Ultimatum Game

\begin{tabular}{ccccc}
\hline Country & Context & Game order & Rejected & Accepted \\
\hline \multirow{3}{*}{ US } & \multirow{2}{*}{ Certain } & Responder & $3(2.5 \%)$ & $12(9.9 \%)$ \\
& & Proposer & $3(2.5 \%)$ & $12(9.9 \%)$ \\
& \multirow{3}{*}{ Uncertain } & Responder & $5(4.1 \%)$ & $11(9.1 \%)$ \\
& Proposer & $4(3.3 \%)$ & $11(9.1 \%)$ \\
\hline \multirow{3}{*}{ JP } & \multirow{2}{*}{ Certain } & Responder & $2(1.7 \%)$ & $13(10.7 \%)$ \\
& \multirow{3}{*}{ Uncertain } & Proposer & $4(3.3 \%)$ & $11(9.1 \%)$ \\
& & Responder & $3(2.5 \%)$ & $12(9.9 \%)$ \\
& & Proposer & $3(2.5 \%)$ & $12(9.9 \%)$ \\
\hline
\end{tabular}

Note. The numbers in each cell represent raw numbers of participants. The percentage is in proportion to the whole. 


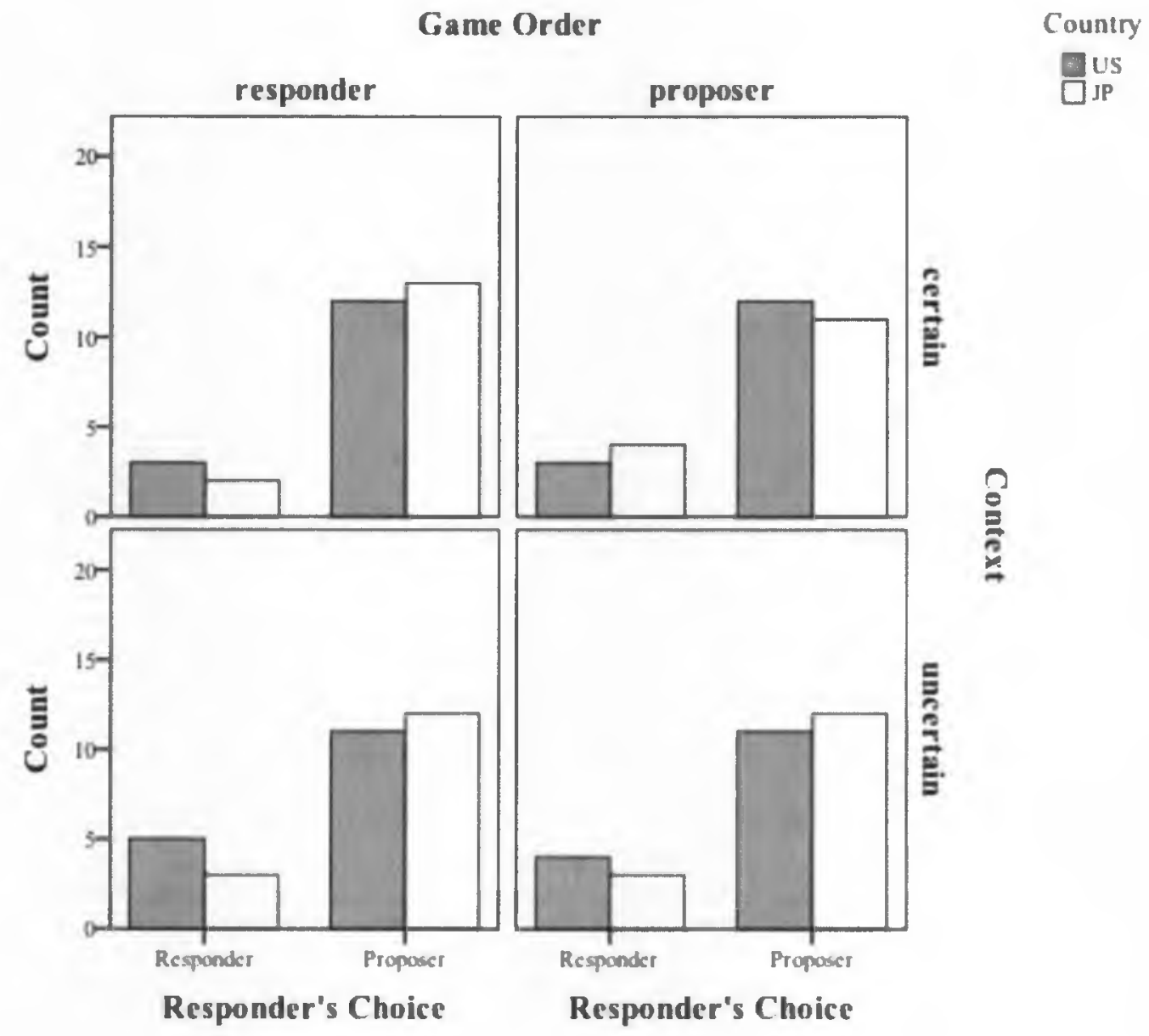

Figure 3. Participants' choice as to accept or reject an unfair offer by another partner during the ultimatum game.

\section{Discussion}

The results from Study 2 supported some hypotheses. Although the Japanese participants did not show higher neuroticism than did the American participants as predicted, the former did show higher intolerance of uncertainty than did the latter. Thus, Hypothesis 1 was not supported, but Hypothesis 2 was. As the cross-cultural comparison on the individual-level individualism dimension revealed, the American participants put 
higher values on uniqueness than did the Japanese participants, whereas the Japanese participants were more accepting of ideas of inequality and competition than were the American participants, lending support for Hypotheses 3 and 4. On the individual-level collectivism dimension, the American participants exhibited relatively higher overall collectivistic values than did the Japanese participants, but this group difference was statistically marginal. This result provided partial support for Hypothesis 5. Individuals in the uncertainty condition exhibited relatively greater cooperative behavior in the ultimatum game than did those in the certainty condition, providing support for Hypothesis 6. When the intolerance of uncertainty was included as a covariate, there was a slight decrease in the effect size of the context on the cooperative behavior. This implied that the intolerance of uncertainty partially accounted for at least some of the effect of the context. In regards to the US-Japan comparison, the Japanese participants in the uncertainty condition generally exhibited greater cooperative behavior than did the American participants in the uncertainty condition, but this group difference did not reach statistical significance. Thus, Hypothesis 7 was not supported. The US-Japan differences in individual differences were not linked with group level differences on cooperative behaviors nor with the effect of uncertainty priming on cooperative behaviors.

The above findings were not generated without limitations. A major limitation was the failure of manipulation checks: individuals in the uncertainty condition did not report higher uncertain feelings than did the certainty condition. Although the pilot survey in Study 1 showed clear effects of the uncertain descriptions on the imagined 
feelings, the experiment in Study 2 failed to replicate the findings in the laboratory. There are some possible explanations to the non-significant ratings. One possibility for such a discrepancy is that the manipulations did produce an effect, but the participants were unaware of it. Another possibility is that instructions on the manipulation checks were ambiguous and led participants to report their overall feelings throughout the entire experiment, which did not specifically point to the effects of manipulations. In addition, the manipulation checks perhaps reflected individual differences in perceptions of the experiment rather than the consequences of the manipulations themselves. This possibility may be indicated by the data that Americans reported higher uncertain feelings than did the Japanese regardless of the conditions. As a whole, these limitations made it difficult to confidently draw a causal inference of uncertainty on the cooperative behaviors between the certainty condition and the uncertainty condition.

The current study found that the Japanese participants did not differ from the American participants on levels of neuroticism. This finding was inconsistent with the previous literature showing that Japanese individuals were typically more neurotic than their North American counterparts (Allik \& McCrae, 2004; McCrae et al., 2005). The inconsistency perhaps resulted from limitations concerning the participants' demographics. First, the Japanese samples in the current study were international students studying at a diverse American university, who may have deviated significantly on neuroticism from the Japanese students studying at local universities. Second, more than half of the American samples in the current study represented ethnic minority groups 
$($ Asians $=26.7 \%$, Hispanic $/$ Latino $=25 \%$, who had been shown to score somewhat higher on anxiety-related traits than the caucasian population (Foldes, Duehr, \& Ones, 2008). Third, the American sample skewed towards female (75.4\%), while the Japanese sample was equally distributed in terms of gender. Schmitt, Realo, Voracek, and Allik (2008) showed that across 55 nations, including U.S. and Japan, women were generally more neurotic than men. Taken together, the US-Japan differences in neuroticism in the current study may have been mitigated by these limitations in the participants' demographics.

\section{General Discussion}

Despite the limitations described above, the current study showed that the uncertainty priming increased the participants' cooperative behaviors. Although the current study failed to show the predicted effects of the manipulation, the finding that individuals in the uncertainty condition showed relatively greater cooperative behavior need an explanation. One possible explanation is that uncertainty implicitly primed the subjects with threat, which tapped into human survival mechanisms; when people are threatened, cooperating even with a stranger may be a strategy that successfully increases one's chance of surviving. This explanation is in accordance with Kollock's theory (1994) that mutual commitment generally occurs when people are put into an uncertain situation. Another potential explanation for the effect of uncertainty on cooperation is that the proposers' cooperation in the current experiment was driven by a fear of rejection, rather than a generous incentive; as people are generally aware of the 
possibility of being rejected in the context of ultimatum game (Fehr \& Fischbacker, 2003), the uncertain condition may have implicitly increased this type of fear, which led subjects to propose a higher sum money in the first round. However, this type of fear was not significantly more apparent in the uncertain condition than in the certain condition, as the manipulation checks failed to capture unconscious responses that the participants may have had during the manipulation phase. Future research may explicitly measure and test the effect of fear on human cooperation.

As expected, the US-Japan difference on the IC values were not as definitive as traditionally theorized, and the analyses on the individual-level differences in the intolerance of uncertainty showed a remarkable US-Japan difference. To our knowledge, the current study was also the first to extend the country-level link between the UA dimension and neuroticism at the individual-level. Since neuroticism and the intolerance of uncertainty were highly correlated, a comparison between Americans and native Japanese on the intolerance of uncertainty would not expectedly differ from the case observed in the current study. These findings challenged the common notion that the IC framework is the most significant account that could explain US-Japan differences in many domains. Instead, the current study suggested that UA dimension may be a more useful dimension on which US-Japan comparison should be made. However, cultural difference in the intolerance of uncertainty was not specifically linked to the cooperative behaviors during the ultimatum game in the current study. Future research may address 
this gap and focus on linking the US-Japan difference in the intolerance of uncertainty with various domains of behaviors.

Some findings, though not relevant to the central research questions, deserve mention. The subjects in the current study generally accepted the unfair offers made by the anonymous partner. This finding was consistent with the assertion that humans are generally cooperative even with an unfamiliar stranger (Fehr \& Fischbacker, 2003). Future research using the ultimatum game paradigm may investigate the possible link between feelings associated with unfairness and cooperative behavior, since the current study did not measure the effect of feelings associated with unfairness on cooperation.

The major objective of the current study was to test whether the UA dimension would produce the US-Japan difference in cooperative behaviors. The uncertainty did not produce any US-Japan differences in cooperative behaviors, but rather increased cooperative behaviors across contexts and cultural backgrounds. US-Japan differences in the IC values and the intolerance of uncertainty implied that the UA dimension would be a better cultural dimension in cross-cultural research examining US-Japan differences. Future directions in this line of research include linking the US-Japan difference on the UA dimension with other relevant behaviors. 


\section{References}

Allik, J., \& McCrae, R. R. (2004). Towards a geography of personality traits: Patterns of profiles across 36 cultures. Journal of Cross-Cultural Psychology, 35, 13-28.

Benedict, R. (1946). The chrysanthemum and the sword: Patterns of Japanese culture. New York NY: Houghton Mifflin Harcourt.

Buchan, N. R., Croson, R. T., \& Johnson, E. J. (2004). When do fair beliefs influence bargaining behavior? Experimental bargaining in Japan and the United States. Journal of Consumer Research, 31, 181-190.

Buhr, K., \& Dugas, M. J. (2002). The intolerance of uncertainty scale: Psychometric properties of the English version. Behaviour Research and Therapy, 40, 931-945.

Cook, K. S., Yamagishi, T., Cheshire, C., Cooper, R., Matsuda, M., \& Mashima, R. (2005). Trust building via risk taking: A cross-societal experiment. Social Psychology Quarterly, 68, 121-142.

Costa, P. T, Jr., \& McCrae, R. R. (1992). Revised NEO Personality Inventory (NEO-PIR) and NEO Five-Factor Inventory (NEO-FFI) manual. Odessa, FL: Psychological Assessment Resources.

Dawes, R. M. (1980). Social dilemmas. Annual review of psychology, 31, 169-193.

Doi, T. (1973). The anatomy of dependince. Tokyo: Kodansha International.

Fehr, E., \& Fischbacher, U. (2003). The nature of human altruism. Nature, 425, 785-791. Fischbacher, U. (2007). Z-tree: Zurich toolbox for ready-made economic experiments. Experimental Economics, 10, 171-178. 
Foldes, H. J., Duehr, E. E., \& Ones, D. S. (2008). Group differences in personality: Metaanalyses comparing five US racial groups. Personnel Psychology, 61, 579-616.

Freeston, M. H., Rhe'aume, J., Letarte, H., Dugas, M. J., \& Ladouceur, R. (1994). Why do people worry? Personality and Individual Differences, 17, 791-802.

Güth, W., Schmittberger, R., \& Schwarze, B. (1982). An experimental analysis of ultimatum bargaining. Journal of Economic Behavior \& Organization, 3, 367388.

Hamamura, T. (2012). Are cultures becoming individualistic? A cross-temporal comparison of individualism-collectivism in the United States and Japan. Personality and Social Psychology Review, 16, 3-24.

Hayashi, N., Ostrom, E., Walker, J., \& Yamagishi, T. (1999). Reciprocity, trust, and the sense of control: A cross-societal study. Rationality and Society, 11, 27-46.

Heine, S. J., Lehman, D. R., Peng, K.. \& Greenholtz, J. (2002). What's wrong with crosscultural comparisons of subjective Likert scales?: The reference-group effect. Journal of Personality and Social Psychology, 82, 903-918.

Henrich, J., Boyd, R., Bowles, S., Camerer, C., Fehr, E., Gintis, H., \& McElreath, R. (2001). In search of homo economicus: Behavioral experiments in 15 small-scale societies. The American Economic Review, 91, 73-78.

Hofstede, G. (1980). Culture's consequences: International differences in work-related values. Beverly Hills CA: Sage. 
Hofstede, G. (2001). Culture's consequences: Comparing values, behaviors, institutions and organizations across nations ( $2^{\text {nd }}$ edn.). Thousand Oaks CA: Sage.

Hofstede, G., \& McCrae, R. R. (2004). Personality and culture revisited: Linking traits and dimensions of culture. Cross-Cultural Research, 38, 52-88.

Iyengar, S. S., \& Lepper, M. R. (1999). Rethinking the value of choice: A cultural perspective on intrinsic motivation. Journal of Personality and Social Psychology, 76, 349-366.

Kemmelmeier, M., Burnstein, E., Krumov, K., Genkova, P., Kanagawa, C., Hirshberg, S., ... Noels, A. (2003). Individualism, collectivism, and authoritarianism in seven societies. Journal of Cross-Cultural Psychology, 34, 304-322.

Kim, K. I., Park, H. J., \& Suzuki, N. (1990). Reward allocations in the United States, Japan, and Korea: A comparison of individualistic and collectivistic cultures. Academy of Management Journal, 33, 188-198.

Kitayama, S., Markus, H. R., \& Kurokawa, M. (2000). Culture, emotion, and well-being: Good feelings in Japan and the United States. Cognition \& Emotion, 14, 93-124. Kollock, P. (1994). The emergence of exchange structures: An experimental study of uncertainty, commitment, and trust. American Journal of Sociology, 100, 313345.

Lebra, T. S. (1976). Japanese patterns of behaviour. Honolulu HI: University of Hawaii Press. 
Markus, H. R., \& Kitayama, S. (1991). Culture and the self: Implications for cognition, emotion, and motivation. Psychological Review, 98, 224-253.

Markus, H. R., \& Kitayama, S. (2001). The cultural construction of self and emotion: Implications for social behavior. Emotions in social psychology: Essential Reading, 119-137.

Mashima, R., Yamagishi, T., \& Macy, M. (2004). Trust and cooperation: A comparison of in-group preference and trust behavior between American and Japanese students. The Japanese Journal of Psychology, 75, 308-315.

Matsumoto, D. (1999). Culture and self: An empirical assessment of Markus and Kitayama's theory of independent and interdependent self-construals. Asian Journal of Social Psychology, 2, 289-310.

Matsumoto, D. (2002). The new Japan: Debunking seven cultural stereotypes. Boston MA: Intercultural Press.

Matsumoto, D. (2006). Are cultural differences in emotion regulation mediated by personality traits? Journal of Cross-Cultural Psychology, 37, 421-437.

Matsumoto, D., \& Juang, L. (2013). Culture and psychology. Belmont CA: Wadsworth, Cengage Learning.

Matsumoto, D., \& Yoo, S. H. (2006). Toward a new generation of cross-cultural research. Perspectives on Psychological Science, 1, 234-250. 
McCrae, R. R., Terracciano, A., \& 79 members of the Personality Profiles of Cultures Project. (2005). Personality profiles of cultures: Aggregate personality traits. Journal of Personality and Social Psychology, 89, 407-425.

Nisbett, R. E., Peng, K., Choi, I., \& Norenzayan, A. (2001). Culture and systems of thought: Holistic versus analytic cognition. Psychological Review, 108, 291-310.

Oishi, S., Diener, E. F., Lucas, R. E., \& Suh, E. M. (1999). Cross-cultural variations in predictors of life satisfaction: Perspectives from needs and values. Personality and Social Psychology Bulletin, 25, 980-990.

Oosterbeek, H., Sloof, R., \& Van De Kuilen, G. (2004). Cultural differences in ultimatum game experiments: Evidence from a meta-analysis. Experimental Economics, 7 , 171-188.

Oyserman, D., Coon, H. M., \& Kemmelmeier, M. (2002). Rethinking individualism and collectivism: Evaluation of theoretical assumptions and meta-analyses. Psychological Bulletin, 128, 3-72.

Oyserman, D., \& Lee, S. W. (2008). Does culture influence what and how we think? Effects of priming individualism and collectivism. Psychological Bulletin, 134, 311-342.

Roth, A. E., Prasnikar, V., Okuno-Fujiware, M., \& Zamir, S. (1991). Bargaining and market behavior and human decision processes. The American Economic Review, 72, 256-279. 
Schmitt, D. P., Realo, A., Voracek, M., \& Allik, J. (2008). Why can't a man be more like a woman? Sex differences in Big Five personality traits across 55 cultures. Journal of Personality and Social Psychology, 94, 168-182.

Singelis, T. M., Triandis, H. C., Bhawuk, D. P., \& Gelfand, M. J. (1995). Horizontal and vertical dimensions of individualism and collectivism: A theoretical and measurement refinement. Cross-Cultural Research, 29, 240-275.

Smith, C. A., \& Ellsworth, P. C. (1985). Patterns of cognitive appraisal in emotion. Journal of Personality and Social Psychology, 48, 813-838.

Takano,Y., \& Osaka,E. (1999). An unsupported common view: Comparing Japan and the U.S. on individualism/collectivism. Asian Journal of Social Psychology, 2, 311 341.

Takano, Y., \& Sogon, S. (2008). Are Japanese more collectivistic than Americans? Examining conformity in in-groups and the reference-group effect. Journal of Cross-Cultural Psychology, 39, 237-250.

Triandis, H. C. (1995). Individualism and collectivism. Boulder CO: Westview Press. Taras, V., Kirkman, B. L., \& Steel, P. (2010). Examining the impact of culture's consequences: A three decade, multilevel, meta-analytic review of Hofstede's cultural value dimensions. Journal of Applied Psychology, 95, 405-439.

Taras, V., Sarala, R., Muchinsky, P., Kemmelmeier, M., Singelis, T. M., Avsec, A., ... Sinclair, C. (2014). Opposite ends of the same stick? Multi-method test of the 
dimensionality of individualism and collectivism. Journal of Cross-Cultural Psychology, 45, 213-245.

Wade-Benzoni, K. A., Okumura, T., Brett, J. M., Moore, D. A., Tenbrunsel, A. E., \& Bazerman, M. H. (2002). Cognitions and behavior in asymmetric social dilemmas: A comparison of two cultures. Journal of Applied Psychology, 87, 8795.

Watson, D., Clark, L. A., \& Tellegen, A. (1988). Development and validation of brief measures of positive and negative affect: The PANAS scales. Journal of Personality and Social Psychology, 54, 1063-1070.

Yamagishi, T. (1988). The provision of a sanctioning system in the United States and Japan. Social Psychology Quarterly, 51, 265-271.

Yamagishi, T., Cook, K. S., \& Watabe, M. (1998). Uncertainty, trust, and commitment formation in the United States and Japan. American Journal of Sociology, 104, 165-194.

Yamagishi, T., Hashimoto, H., \& Schug. J. (2008). Preferences versus strategies as explanations for culture-specific behavior. Psychological Science, 19, 579-584.

Yamagishi, T., Makimura, Y., Foddy, M., Matsuda, M., Kiyonari, T., \& Platow, M. J. (2005). Comparisons of Australians and Japanese on group-based cooperation. Asian Journal of Social Psychology, 8, 173-190. 
Yamagishi, T., Mifune, N., Liu, J. H., \& Pauling, J. (2008). Exchanges of group-based favours: Ingroup bias in the prisoner's dilemma game with minimal groups in Japan and New Zealand. Asian Journal of Social Psychology, 11, 196-207.

Zhou, B., Lacroix, F., Sasaki, J., Peng, Y., Wang, X., \& Ryder, A. (2014). Unpacking cultural variations in social anxiety and the offensive-type of taijin kyofusho through the indirect effects of intolerance of uncertainty and self-construals. Journal of Cross-Cultural Psychology, 45, 1561-1578. 


\author{
Appendix A \\ San Francisco State University \\ Consent to Participate in Research \\ Perceptions on Psychological Experiment
}

Purpose: The purpose of this survey is to examine how people perceive characteristics of a context within which they may be asked to complete some tasks for a psychological study. The principal investigator, Kodai Kusano, is a Master's student in the Psychology Department at San Francisco State University. His advisor, David Matsumoto, is a Professor in the Psychology Department at San Francisco State University. YOU MUST BE 18 or OLDER TO PARTICIPATE.

Procedures: Please complete the survey in one sitting. You must complete the survey in a PRIVATE and quiet environment that is free of distractions. It approximately takes 30 minutes to complete the survey.

Risks: There is a risk of loss of privacy. However, no names or identities will be used in any published reports of the research.

Confidentiality: All of your responses will be confidential. Your responses will only be identified by a number. Your responses will be kept in a password-protected program and only the researchers involved in this study will have access to the information you provide. Any electronic documents with identifiable information will be encrypted. The data will be kept for a period of three years, after which it will be destroyed.

Direct Benefits: There will be no direct benefits to the participant.

Payment: There will be no payment for participant. 
Costs: There will be no cost to you for participating in this research.

Compensation: 0.5 SONA credit.

Alternatives: The alternative is not to participate in the research.

Voluntary Participation: You are free to decline to participate in this research survey, or to withdraw your participation at any point, without penalty.

Questions: Questions about your rights as a study participant, or comments or complaints about the study, may also be addressed to the Office for the Protection of Human Subjects at 415: 338-1093 or protocol@sfsu.edu.

Any questions or concerns should be directed to the principal investigator, Kodai Kusano by email at kusano@mail.sfsu.edu or the research advisor, Professor David Matsumoto at dm@sfsu.edu.

Are you 18 years of age or older?

O Yes (1)

O No (2)

Q47 Research designs often require that the full intent of the study not be explained prior to participation. When the study is completed, you will receive a full debriefing on the purpose and the procedures of the research. 


\section{Instruction}

This survey investigates people's general moods/feelings to a psychological experiment. A psychological experiment often asks you to perform a task with a partner in a laboratory. The researcher is interested in how you would feel about the rule of the task, the structure of the experiment, or the physical environment within which you may be asked to perform the task with the partner. The purpose of the survey is to get a clear idea of how to set a psychological experiment.

Please imagine that you are a participant in a psychological experiment in answering the following questions. The questions first tell you about a basic context in which you will be. Then each question consists of a pair of descriptions, A and B, slightly different from each other. Your task is to evaluate these imaginary descriptions for each context.

Q50 You will see an example question on the next page. 


\section{Example}

The following are descriptions of aspects of a context within which you may be asked to complete some tasks.

Please imagine that you are the participant with a partner in the described context.

Evaluate to what extent each description would evoke the following feelings if you were in the situation by using the scale from 1 to 9 .

$1($ Not at all $)=$ "doesn't evoke the feeling at all"

5 (Moderate) $=$ "evokes moderate amount of the feeling"

$9($ Extremely $)=$ "evokes extreme amount of the feeling".

e.g. Example Context) Upon arrival at the laboratory, the experimenter gives you one of the following instructions: 
e.g. Description A. You will receive money depending on your performance as a compensation.

\begin{tabular}{|c|c|c|c|c|c|c|c|c|c|}
\hline & $1(1)$ & $2(2)$ & $3(3)$ & $4(4)$ & $5(5)$ & $6(6)$ & $7(7)$ & $8(8)$ & $9(9)$ \\
\hline $\begin{array}{l}\text { Ambiguous } \\
\text { (1) }\end{array}$ & 0 & 0 & 0 & 0 & 0 & 0 & 0 & 0 & 0 \\
\hline Inspired (2) & 0 & 0 & 0 & 0 & 0 & 0 & 0 & 0 & 0 \\
\hline Afraid (3) & 0 & 0 & 0 & 0 & 0 & 0 & O & $\mathrm{O}$ & 0 \\
\hline Hostile (4) & 0 & 0 & 0 & O & 0 & 0 & O & 0 & 0 \\
\hline Strong (5) & 0 & 0 & 0 & 0 & 0 & 0 & 0 & 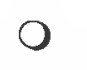 & 0 \\
\hline Upset (6) & O & 0 & 0 & 0 & 0 & 0 & $\mathrm{O}$ & 0 & 0 \\
\hline Active (7) & 0 & $\mathrm{O}$ & 0 & 0 & 0 & 0 & O & 0 & 0 \\
\hline $\begin{array}{c}\text { Uncertain } \\
\text { (8) }\end{array}$ & 0 & 0 & 0 & O & 0 & 0 & 0 & 0 & O \\
\hline $\begin{array}{l}\text { Unexpected } \\
\text { (9) }\end{array}$ & 0 & 0 & 0 & O & 0 & 0 & 0 & 0 & 0 \\
\hline $\begin{array}{l}\text { Unsettled } \\
(10)\end{array}$ & 0 & 0 & 0 & 0 & 0 & 0 & 0 & 0 & 0 \\
\hline Jittery (11) & 0 & 0 & 0 & 0 & $\mathrm{O}$ & 0 & 0 & $O$ & 0 \\
\hline $\begin{array}{l}\text { Excited } \\
\text { (12) }\end{array}$ & 0 & 0 & 0 & O & 0 & 0 & O & 0 & 0 \\
\hline Proud (13) & 0 & 0 & 0 & 0 & 0 & 0 & 0 & 0 & 0 \\
\hline $\begin{array}{l}\text { Interested } \\
\text { (14) }\end{array}$ & 0 & 0 & 0 & 0 & 0 & 0 & O & 0 & 0 \\
\hline $\begin{array}{c}\text { Enthusiastic } \\
\text { (15) }\end{array}$ & 0 & 0 & 0 & O & $\mathrm{O}$ & $\mathrm{O}$ & O & 0 & 0 \\
\hline $\begin{array}{c}\text { Anxious } \\
\text { (16) }\end{array}$ & 0 & 0 & 0 & 0 & 0 & O & 0 & 0 & 0 \\
\hline $\begin{array}{c}\text { Surprised } \\
\text { (17) }\end{array}$ & 0 & 0 & 0 & O & 0 & 0 & O & O & 0 \\
\hline Scared (18) & 0 & $\mathrm{O}$ & O & O & 0 & 0 & 0 & 0 & 0 \\
\hline $\begin{array}{l}\text { Determined } \\
\text { (19) }\end{array}$ & 0 & 0 & 0 & 0 & 0 & 0 & 0 & O & $\mathrm{O}$ \\
\hline $\begin{array}{l}\text { Attentive } \\
\text { (20) }\end{array}$ & $\mathrm{O}$ & 0 & 0 & 0 & 0 & 0 & 0 & 0 & 0 \\
\hline
\end{tabular}


e.g. Description B. You will receive a gift card instead of money as a compensation.

\begin{tabular}{|c|c|c|c|c|c|c|c|c|c|}
\hline & $1(1)$ & $2(2)$ & $3(3)$ & $4(4)$ & $5(5)$ & $6(6)$ & $7(7)$ & $8(8)$ & $9(9)$ \\
\hline $\begin{array}{l}\text { Ambiguous } \\
\text { (1) }\end{array}$ & 0 & 0 & 0 & 0 & $\mathrm{O}$ & 0 & $\mathrm{O}$ & $\mathrm{O}$ & 0 \\
\hline Inspired (2) & O & 0 & 0 & O & $O$ & $\mathrm{O}$ & $\mathrm{O}$ & O & $\mathrm{O}$ \\
\hline Afraid (3) & 0 & $O$ & $\mathrm{O}$ & O & $\mathrm{O}$ & $\mathrm{O}$ & O & O & O \\
\hline Hostile (4) & $\mathrm{O}$ & 0 & 0 & 0 & 0 & 0 & O & 0 & 0 \\
\hline Strong (5) & 0 & 0 & 0 & O & 0 & 0 & 0 & 0 & 0 \\
\hline Upset (6) & 0 & O & 0 & 0 & 0 & 0 & 0 & O & 0 \\
\hline Active (7) & $\mathrm{O}$ & O & $\mathrm{O}$ & 0 & 0 & O & 0 & O & $O$ \\
\hline $\begin{array}{c}\text { Uncertain } \\
(8)\end{array}$ & $\mathrm{O}$ & 0 & 0 & O & 0 & $\mathrm{O}$ & $\mathrm{O}$ & 0 & 0 \\
\hline $\begin{array}{l}\text { Unexpected } \\
\text { (9) }\end{array}$ & O & 0 & 0 & O & 0 & 0 & $\mathrm{O}$ & $\mathrm{O}$ & O \\
\hline $\begin{array}{l}\text { Unsettled } \\
(10)\end{array}$ & $\mathrm{O}$ & $\mathrm{O}$ & 0 & $\mathrm{O}$ & 0 & 0 & 0 & 0 & 0 \\
\hline Jittery (11) & O & 0 & 0 & 0 & O & 0 & $\mathrm{O}$ & $\mathrm{O}$ & 0 \\
\hline $\begin{array}{l}\text { Excited } \\
\text { (12) }\end{array}$ & 0 & 0 & 0 & O & 0 & 0 & 0 & $\mathrm{O}$ & $\mathrm{O}$ \\
\hline Proud (13) & 0 & 0 & 0 & O & O & $\mathrm{O}$ & $O$ & $O$ & 0 \\
\hline $\begin{array}{l}\text { Interested } \\
\text { (14) }\end{array}$ & 0 & 0 & 0 & 0 & 0 & 0 & 0 & 0 & $\mathrm{O}$ \\
\hline $\begin{array}{l}\text { Enthusiastic } \\
\text { (15) }\end{array}$ & 0 & 0 & 0 & 0 & O & $\mathrm{O}$ & 0 & 0 & O \\
\hline $\begin{array}{l}\text { Anxious } \\
(16)\end{array}$ & 0 & 0 & $O$ & O & $\mathrm{O}$ & 0 & 0 & 0 & 0 \\
\hline $\begin{array}{c}\text { Surprised } \\
\text { (17) }\end{array}$ & 0 & 0 & 0 & $\mathrm{O}$ & $\mathrm{O}$ & $\mathrm{O}$ & O & 0 & $\mathrm{O}$ \\
\hline Scared (18) & 0 & 0 & 0 & 0 & 0 & 0 & 0 & $O$ & $\mathrm{O}$ \\
\hline $\begin{array}{l}\text { Determined } \\
\text { (19) }\end{array}$ & 0 & 0 & $\mathrm{O}$ & 0 & 0 & 0 & O & 0 & 0 \\
\hline $\begin{array}{c}\text { Attentive } \\
(20)\end{array}$ & 0 & 0 & 0 & 0 & 0 & 0 & 0 & 0 & O \\
\hline
\end{tabular}


Q56 The actual survey begins from the next page and your response will be recorded. There are seven questions (contexts).

1 Context. Your performance on the task is dependent on a computer that you will use. The computer will be in one of the following contexts: 
1A A. The computer you will be working on has performed well with no technical problems so far.

\begin{tabular}{|c|c|c|c|c|c|c|c|c|c|}
\hline & $1(1)$ & $2(2)$ & $3(3)$ & $4(4)$ & $5(5)$ & $6(6)$ & $7(7)$ & $8(8)$ & $9(9)$ \\
\hline $\begin{array}{l}\text { Ambiguous } \\
\text { (1) }\end{array}$ & $O$ & 0 & 0 & 0 & $\mathrm{O}$ & O & $\mathrm{O}$ & $\mathrm{O}$ & 0 \\
\hline Inspired (2) & 0 & 0 & 0 & 0 & 0 & 0 & 0 & $\mathrm{O}$ & 0 \\
\hline Afraid (3) & 0 & 0 & 0 & 0 & 0 & 0 & 0 & 0 & 0 \\
\hline Hostile (4) & 0 & 0 & 0 & 0 & 0 & 0 & 0 & 0 & 0 \\
\hline Strong (5) & 0 & O & 0 & 0 & O & O & 0 & O & $\mathrm{O}$ \\
\hline Upset (6) & $\mathrm{O}$ & $\mathrm{O}$ & 0 & $\mathrm{O}$ & O & 0 & 0 & O & 0 \\
\hline Active (7) & 0 & 0 & 0 & $\mathrm{O}$ & 0 & 0 & 0 & 0 & 0 \\
\hline $\begin{array}{l}\text { Uncertain } \\
(8)\end{array}$ & 0 & 0 & 0 & 0 & 0 & O & 0 & 0 & O \\
\hline $\begin{array}{l}\text { Unexpected } \\
\text { (9) }\end{array}$ & 0 & 0 & 0 & O & 0 & 0 & 0 & 0 & 0 \\
\hline $\begin{array}{l}\text { Unsettled } \\
\text { (10) }\end{array}$ & $\mathrm{O}$ & 0 & 0 & 0 & 0 & 0 & 0 & 0 & 0 \\
\hline Jittery (11) & 0 & 0 & 0 & 0 & 0 & 0 & 0 & O & 0 \\
\hline $\begin{array}{l}\text { Excited } \\
(12)\end{array}$ & 0 & 0 & 0 & O & 0 & 0 & 0 & 0 & 0 \\
\hline Proud (13) & 0 & 0 & 0 & 0 & 0 & 0 & 0 & O & $\mathrm{O}$ \\
\hline $\begin{array}{c}\text { Interested } \\
\text { (14) }\end{array}$ & O & 0 & 0 & O & $\mathrm{O}$ & O & 0 & 0 & 0 \\
\hline $\begin{array}{c}\text { Enthusiastic } \\
\text { (15) }\end{array}$ & O & 0 & 0 & 0 & 0 & 0 & 0 & 0 & 0 \\
\hline $\begin{array}{l}\text { Anxious } \\
(16)\end{array}$ & O & 0 & 0 & 0 & O & $\mathrm{O}$ & 0 & 0 & $\mathrm{O}$ \\
\hline $\begin{array}{l}\text { Surprised } \\
\text { (17) }\end{array}$ & O & O & 0 & O & O & O & 0 & 0 & 0 \\
\hline Scared (18) & 0 & 0 & 0 & $\mathrm{O}$ & 0 & 0 & 0 & 0 & O \\
\hline $\begin{array}{l}\text { Determined } \\
\text { (19) }\end{array}$ & 0 & 0 & 0 & 0 & O & O & 0 & O & 0 \\
\hline $\begin{array}{l}\text { Attentive } \\
(20)\end{array}$ & $\mathrm{O}$ & 0 & 0 & 0 & 0 & 0 & 0 & 0 & 0 \\
\hline
\end{tabular}


1B B. The computer you will be working on has accidentally frozen or shut down once in a while in the past.

\begin{tabular}{|c|c|c|c|c|c|c|c|c|c|}
\hline & $1(1)$ & $2(2)$ & $3(3)$ & $4(4)$ & $5(5)$ & $6(6)$ & $7(7)$ & $8(8)$ & $9(9)$ \\
\hline $\begin{array}{l}\text { Ambiguous } \\
\text { (1) }\end{array}$ & 0 & 0 & 0 & 0 & 0 & 0 & 0 & 0 & 0 \\
\hline Inspired (2) & $O$ & 0 & $\mathrm{O}$ & $O$ & 0 & $\mathrm{O}$ & 0 & 0 & 0 \\
\hline Afraid (3) & 0 & 0 & 0 & 0 & 0 & 0 & 0 & 0 & 0 \\
\hline Hostile (4) & 0 & 0 & 0 & 0 & 0 & 0 & 0 & 0 & $\mathrm{O}$ \\
\hline Strong (5) & 0 & 0 & $\mathrm{O}$ & 0 & 0 & 0 & 0 & 0 & 0 \\
\hline Upset (6) & 0 & 0 & 0 & 0 & 0 & 0 & 0 & 0 & 0 \\
\hline Active (7) & 0 & 0 & 0 & 0 & 0 & 0 & 0 & 0 & 0 \\
\hline $\begin{array}{l}\text { Uncertain } \\
\text { (8) }\end{array}$ & 0 & 0 & 0 & 0 & 0 & 0 & 0 & 0 & 0 \\
\hline $\begin{array}{l}\text { Unexpected } \\
\text { (9) }\end{array}$ & 0 & 0 & 0 & 0 & 0 & 0 & 0 & 0 & $\mathrm{O}$ \\
\hline $\begin{array}{l}\text { Unsettled } \\
\text { (10) }\end{array}$ & 0 & 0 & 0 & 0 & 0 & 0 & 0 & $O$ & $O$ \\
\hline Jittery (11) & 0 & 0 & 0 & 0 & $\mathrm{O}$ & 0 & 0 & 0 & $\mathrm{O}$ \\
\hline $\begin{array}{l}\text { Excited } \\
\text { (12) }\end{array}$ & 0 & 0 & 0 & 0 & 0 & 0 & 0 & 0 & 0 \\
\hline Proud (13) & 0 & 0 & $\mathrm{O}$ & $O$ & $\mathrm{O}$ & 0 & 0 & 0 & 0 \\
\hline $\begin{array}{l}\text { Interested } \\
\text { (14) }\end{array}$ & 0 & 0 & 0 & 0 & 0 & 0 & 0 & 0 & O \\
\hline $\begin{array}{c}\text { Enthusiastic } \\
\text { (15) }\end{array}$ & 0 & 0 & 0 & 0 & 0 & 0 & 0 & 0 & 0 \\
\hline $\begin{array}{c}\text { Anxious } \\
(16)\end{array}$ & 0 & 0 & 0 & 0 & 0 & 0 & 0 & 0 & 0 \\
\hline $\begin{array}{c}\text { Surprised } \\
\text { (17) }\end{array}$ & 0 & 0 & 0 & 0 & 0 & 0 & 0 & 0 & 0 \\
\hline Scared (18) & 0 & 0 & 0 & 0 & 0 & $\mathrm{O}$ & 0 & O & $O$ \\
\hline $\begin{array}{l}\text { Determined } \\
\text { (19) }\end{array}$ & 0 & 0 & 0 & 0 & 0 & 0 & 0 & 0 & 0 \\
\hline $\begin{array}{c}\text { Attentive } \\
\text { (20) }\end{array}$ & 0 & 0 & 0 & 0 & O & 0 & 0 & 0 & 0 \\
\hline
\end{tabular}


2 Context. Your performance on the task is dependent on an alarm that you will use. The alarm will be in one of the following contexts:

2A A. The alarm on the table has been functioning well and will go off reliably when the game is complete.

\begin{tabular}{|c|c|c|c|c|c|c|c|c|c|}
\hline & I (1) & $2(2)$ & $3(3)$ & $4(4)$ & $5(5)$ & $6(6)$ & $7(7)$ & $8(8)$ & $9(9)$ \\
\hline $\begin{array}{c}\text { Ambiguous } \\
\text { (1) }\end{array}$ & 0 & 0 & 0 & 0 & 0 & 0 & O & 0 & O \\
\hline Inspired (2) & 0 & 0 & 0 & 0 & 0 & 0 & 0 & 0 & 0 \\
\hline Afraid (3) & 0 & 0 & 0 & 0 & 0 & 0 & 0 & 0 & 0 \\
\hline Hostile (4) & O & 0 & 0 & 0 & 0 & 0 & O & 0 & O \\
\hline Strong (5) & 0 & 0 & O & 0 & 0 & O & 0 & 0 & O \\
\hline Upset (6) & 0 & 0 & 0 & 0 & 0 & 0 & 0 & 0 & 0 \\
\hline Active (7) & 0 & 0 & 0 & 0 & 0 & 0 & 0 & 0 & $\mathrm{O}$ \\
\hline $\begin{array}{l}\text { Uncertain } \\
(8)\end{array}$ & 0 & 0 & O & 0 & 0 & 0 & 0 & 0 & 0 \\
\hline $\begin{array}{l}\text { Unexpected } \\
\text { (9) }\end{array}$ & 0 & 0 & 0 & 0 & O & $\mathrm{O}$ & 0 & 0 & 0 \\
\hline $\begin{array}{l}\text { Unsettled } \\
\text { (10) }\end{array}$ & 0 & 0 & 0 & 0 & 0 & 0 & 0 & 0 & 0 \\
\hline Jittery (11) & 0 & 0 & 0 & 0 & O & 0 & 0 & 0 & 0 \\
\hline $\begin{array}{l}\text { Excited } \\
\text { (12) }\end{array}$ & 0 & O & 0 & 0 & O & 0 & 0 & 0 & 0 \\
\hline Proud (13) & O & O & O & 0 & O & $\mathrm{O}$ & O & 0 & 0 \\
\hline $\begin{array}{l}\text { Interested } \\
\text { (14) }\end{array}$ & 0 & 0 & O & 0 & O & $\mathrm{O}$ & O & 0 & 0 \\
\hline $\begin{array}{l}\text { Enthusiastic } \\
\text { (15) }\end{array}$ & 0 & 0 & 0 & 0 & 0 & 0 & 0 & 0 & 0 \\
\hline $\begin{array}{l}\text { Anxious } \\
\text { (16) }\end{array}$ & 0 & 0 & 0 & 0 & 0 & 0 & 0 & 0 & 0 \\
\hline $\begin{array}{l}\text { Surprised } \\
\text { (17) }\end{array}$ & 0 & O & 0 & 0 & O & O & 0 & 0 & 0 \\
\hline Scared (18) & 0 & 0 & 0 & 0 & 0 & 0 & 0 & 0 & 0 \\
\hline $\begin{array}{l}\text { Determined } \\
\text { (19) }\end{array}$ & 0 & O & 0 & 0 & 0 & 0 & 0 & 0 & O \\
\hline
\end{tabular}




\begin{tabular}{|c|l|l|l|l|l|l|l|l|l|}
\hline $\begin{array}{c}\text { Attentive } \\
(20)\end{array}$ & 0 & 0 & 0 & 0 & 0 & 0 & 0 & 0 & $O$ \\
\hline
\end{tabular}

2B B. The alarm on the table will randomly go off to indicate the end of the game.

\begin{tabular}{|c|c|c|c|c|c|c|c|c|c|}
\hline & I (1) & $2(2)$ & $3(3)$ & $4(4)$ & $5(5)$ & $6(6)$ & $7(7)$ & $8(8)$ & $9(9)$ \\
\hline $\begin{array}{l}\text { Ambiguous } \\
\text { (1) }\end{array}$ & 0 & 0 & 0 & O & 0 & 0 & 0 & O & 0 \\
\hline Inspired (2) & 0 & $\mathrm{O}$ & $\mathrm{O}$ & 0 & $\mathrm{O}$ & $\mathrm{O}$ & $\mathrm{O}$ & 0 & 0 \\
\hline Afraid (3) & $\mathrm{O}$ & 0 & 0 & 0 & 0 & $\mathrm{O}$ & 0 & 0 & 0 \\
\hline Hostile (4) & 0 & 0 & 0 & 0 & 0 & O & 0 & O & $O$ \\
\hline Strong (5) & 0 & 0 & 0 & 0 & 0 & O & 0 & $\mathrm{O}$ & $O$ \\
\hline Upset (6) & 0 & $O$ & $\mathrm{O}$ & 0 & $\mathrm{O}$ & $\mathrm{O}$ & $\mathrm{O}$ & $\mathrm{O}$ & 0 \\
\hline Active (7) & 0 & 0 & O & 0 & 0 & 0 & 0 & 0 & 0 \\
\hline $\begin{array}{c}\text { Uncertain } \\
(8)\end{array}$ & 0 & 0 & O & $O$ & $\mathrm{O}$ & $\mathrm{O}$ & $\mathrm{O}$ & 0 & 0 \\
\hline $\begin{array}{l}\text { Unexpected } \\
\text { (9) }\end{array}$ & 0 & 0 & 0 & 0 & 0 & 0 & 0 & 0 & 0 \\
\hline $\begin{array}{l}\text { Unsettled } \\
\text { (10) }\end{array}$ & 0 & 0 & $\mathrm{O}$ & O & 0 & $\mathrm{O}$ & 0 & 0 & 0 \\
\hline Jittery (11) & 0 & 0 & 0 & 0 & 0 & 0 & 0 & 0 & 0 \\
\hline $\begin{array}{l}\text { Excited } \\
(12)\end{array}$ & 0 & 0 & 0 & O & 0 & 0 & 0 & 0 & O \\
\hline Proud (13) & 0 & 0 & 0 & 0 & $\mathrm{O}$ & $O$ & $\mathrm{O}$ & $\mathrm{O}$ & $O$ \\
\hline $\begin{array}{l}\text { Interested } \\
\text { (14) }\end{array}$ & 0 & 0 & 0 & 0 & 0 & 0 & O & 0 & 0 \\
\hline $\begin{array}{c}\text { Enthusiastic } \\
\text { (15) }\end{array}$ & 0 & 0 & 0 & 0 & 0 & 0 & 0 & 0 & 0 \\
\hline $\begin{array}{c}\text { Anxious } \\
(16)\end{array}$ & 0 & 0 & 0 & O & 0 & 0 & 0 & 0 & $O$ \\
\hline $\begin{array}{c}\text { Surprised } \\
\text { (17) }\end{array}$ & 0 & 0 & 0 & O & 0 & $\mathrm{O}$ & 0 & 0 & $O$ \\
\hline Scared (18) & O & 0 & 0 & 0 & 0 & 0 & 0 & 0 & 0 \\
\hline $\begin{array}{l}\text { Determined } \\
\text { (19) }\end{array}$ & 0 & 0 & 0 & 0 & 0 & 0 & 0 & 0 & O \\
\hline
\end{tabular}




\begin{tabular}{|c|c|c|c|c|c|c|c|c|c|}
\hline $\begin{array}{c}\text { Attentive } \\
(20)\end{array}$ & 0 & 0 & 0 & 0 & 0 & 0 & 0 & 0 & 0 \\
\hline
\end{tabular}

3 Context. Your performance on the task is dependent on the lights in the room that you will use. The lights will be in one of the following contexts:

$3 \mathrm{~A} \mathrm{~A}$. The lights in the room have been functioning reliably.

\begin{tabular}{|c|c|c|c|c|c|c|c|c|c|}
\hline & I (1) & $2(2)$ & $3(3)$ & $4(4)$ & $5(5)$ & $6(6)$ & $7(7)$ & $8(8)$ & $9(9)$ \\
\hline $\begin{array}{l}\text { Ambiguous } \\
\text { (1) }\end{array}$ & 0 & 0 & O & 0 & 0 & 0 & O & 0 & 0 \\
\hline Inspired (2) & 0 & 0 & 0 & 0 & 0 & $O$ & $\mathrm{O}$ & 0 & 0 \\
\hline Afraid (3) & 0 & 0 & 0 & 0 & 0 & $\mathrm{O}$ & 0 & 0 & 0 \\
\hline Hostile (4) & 0 & 0 & 0 & O & 0 & 0 & 0 & O & 0 \\
\hline Strong (5) & 0 & $\mathrm{O}$ & 0 & 0 & 0 & $\mathrm{O}$ & 0 & 0 & 0 \\
\hline Upset (6) & 0 & $\mathrm{O}$ & 0 & 0 & 0 & $\mathrm{O}$ & 0 & $\mathrm{O}$ & 0 \\
\hline Active (7) & 0 & $\mathrm{O}$ & $\mathrm{O}$ & $O$ & $\mathrm{O}$ & $\mathrm{O}$ & $\mathrm{O}$ & $\mathrm{O}$ & 0 \\
\hline $\begin{array}{c}\text { Uncertain } \\
(8)\end{array}$ & 0 & $\mathrm{O}$ & 0 & 0 & 0 & $\mathrm{O}$ & 0 & 0 & 0 \\
\hline $\begin{array}{l}\text { Unexpected } \\
\text { (9) }\end{array}$ & 0 & 0 & O & 0 & $\mathrm{O}$ & $\mathrm{O}$ & O & 0 & 0 \\
\hline $\begin{array}{l}\text { Unsettled } \\
(10)\end{array}$ & 0 & 0 & 0 & 0 & 0 & O & O & O & 0 \\
\hline Jittery (11) & O & 0 & 0 & 0 & 0 & 0 & $\mathrm{O}$ & 0 & 0 \\
\hline $\begin{array}{l}\text { Excited } \\
\text { (12) }\end{array}$ & 0 & 0 & 0 & 0 & 0 & O & O & 0 & 0 \\
\hline Proud (13) & $\mathrm{O}$ & $\mathrm{O}$ & O & 0 & $\mathrm{O}$ & $\mathrm{O}$ & $\mathrm{O}$ & $\mathrm{O}$ & $O$ \\
\hline $\begin{array}{c}\text { Interested } \\
\text { (14) }\end{array}$ & 0 & 0 & 0 & 0 & $\mathrm{O}$ & 0 & 0 & 0 & 0 \\
\hline $\begin{array}{l}\text { Enthusiastic } \\
\text { (15) }\end{array}$ & $\mathrm{O}$ & 0 & 0 & 0 & 0 & $\mathrm{O}$ & 0 & 0 & 0 \\
\hline $\begin{array}{c}\text { Anxious } \\
(16)\end{array}$ & 0 & 0 & 0 & 0 & 0 & 0 & 0 & 0 & 0 \\
\hline $\begin{array}{l}\text { Surprised } \\
\text { (17) }\end{array}$ & 0 & 0 & 0 & O & $\mathrm{O}$ & O & 0 & 0 & 0 \\
\hline
\end{tabular}




\begin{tabular}{|c|c|c|c|c|c|c|c|c|c|}
\hline $\begin{array}{c}\text { Scared (18) } \\
\text { Determined } \\
(19)\end{array}$ & 0 & 0 & 0 & 0 & 0 & 0 & 0 & 0 & 0 \\
$\begin{array}{c}\text { Attentive } \\
(20)\end{array}$ & 0 & 0 & 0 & 0 & 0 & 0 & 0 & 0 & 0 \\
\hline
\end{tabular}

3B B. The lights in this room have accidently turned off every once in a while in the past.

\begin{tabular}{|c|c|c|c|c|c|c|c|c|c|}
\hline & $1(1)$ & $2(2)$ & $3(3)$ & $4(4)$ & $5(5)$ & $6(6)$ & $7(7)$ & $8(8)$ & $9(9)$ \\
\hline $\begin{array}{l}\text { Ambiguous } \\
\text { (1) }\end{array}$ & O & 0 & 0 & 0 & 0 & 0 & 0 & 0 & 0 \\
\hline Inspired (2) & O & 0 & 0 & O & $\mathrm{O}$ & O & 0 & $\mathrm{O}$ & $\mathrm{O}$ \\
\hline Afraid (3) & 0 & 0 & 0 & 0 & $\mathrm{O}$ & 0 & 0 & 0 & 0 \\
\hline Hostile (4) & 0 & 0 & 0 & 0 & 0 & 0 & 0 & 0 & 0 \\
\hline Strong (5) & 0 & 0 & 0 & $O$ & $\mathrm{O}$ & $\mathrm{O}$ & 0 & 0 & 0 \\
\hline Upset (6) & 0 & 0 & 0 & 0 & $\mathrm{O}$ & $\mathrm{O}$ & 0 & 0 & 0 \\
\hline Active (7) & 0 & 0 & 0 & 0 & $\mathrm{O}$ & $\mathrm{O}$ & 0 & 0 & 0 \\
\hline $\begin{array}{l}\text { Uncertain } \\
(8)\end{array}$ & 0 & 0 & $\mathrm{O}$ & 0 & 0 & $\mathrm{O}$ & $\mathrm{O}$ & 0 & O \\
\hline $\begin{array}{l}\text { Unexpected } \\
\text { (9) }\end{array}$ & $\mathrm{O}$ & 0 & 0 & 0 & O & 0 & 0 & 0 & 0 \\
\hline $\begin{array}{l}\text { Unsettled } \\
\text { (10) }\end{array}$ & 0 & 0 & 0 & 0 & 0 & $\mathrm{O}$ & 0 & 0 & 0 \\
\hline Jittery (11) & 0 & O & 0 & O & $\mathrm{O}$ & $\mathrm{O}$ & O & $\mathrm{O}$ & $\mathrm{O}$ \\
\hline $\begin{array}{l}\text { Excited } \\
\text { (12) }\end{array}$ & 0 & 0 & 0 & 0 & 0 & $\mathrm{O}$ & 0 & 0 & O \\
\hline Proud (13) & 0 & 0 & 0 & $\mathrm{O}$ & $\mathrm{O}$ & 0 & 0 & 0 & O \\
\hline $\begin{array}{l}\text { Interested } \\
\text { (14) }\end{array}$ & 0 & 0 & 0 & 0 & 0 & $\mathrm{O}$ & 0 & 0 & 0 \\
\hline $\begin{array}{c}\text { Enthusiastic } \\
\text { (15) }\end{array}$ & $\mathrm{O}$ & 0 & 0 & $\mathrm{O}$ & 0 & 0 & O & $\mathrm{O}$ & $\mathrm{O}$ \\
\hline $\begin{array}{l}\text { Anxious } \\
\text { (16) }\end{array}$ & O & 0 & 0 & 0 & O & O & 0 & O & $\mathrm{O}$ \\
\hline $\begin{array}{c}\text { Surprised } \\
\text { (17) }\end{array}$ & O & 0 & 0 & O & 0 & 0 & 0 & 0 & 0 \\
\hline
\end{tabular}




\begin{tabular}{|c|c|c|c|c|c|c|c|c|c|}
\hline $\begin{array}{c}\text { Scared (18) } \\
\begin{array}{c}\text { Determined } \\
(19)\end{array}\end{array}$ & 0 & 0 & 0 & 0 & 0 & 0 & 0 & 0 & 0 \\
$\begin{array}{c}\text { Attentive } \\
(20)\end{array}$ & 0 & 0 & 0 & 0 & 0 & 0 & 0 & 0 & 0 \\
\hline
\end{tabular}

4 Context. Your performance on the task is dependent on the chair in which you will sit. The chair will be in one of the following contexts:

4A A. The chair has recently been replaced with new one for this experiment.

\begin{tabular}{|c|c|c|c|c|c|c|c|c|c|}
\hline & $1(1)$ & $2(2)$ & $3(3)$ & $4(4)$ & $5(5)$ & $6(6)$ & $7(7)$ & $8(8)$ & $9(9)$ \\
\hline $\begin{array}{c}\text { Ambiguous } \\
\text { (1) }\end{array}$ & 0 & 0 & 0 & 0 & $\mathrm{O}$ & 0 & $\mathrm{O}$ & $\mathrm{O}$ & $\mathrm{O}$ \\
\hline Inspired (2) & 0 & 0 & 0 & 0 & O & 0 & 0 & $\mathrm{O}$ & $\mathrm{O}$ \\
\hline Afraid (3) & 0 & $\mathrm{O}$ & 0 & 0 & $\mathrm{O}$ & 0 & 0 & $\mathrm{O}$ & $\mathrm{O}$ \\
\hline Hostile (4) & 0 & 0 & 0 & 0 & 0 & 0 & $\mathrm{O}$ & 0 & 0 \\
\hline Strong (5) & 0 & 0 & 0 & 0 & 0 & 0 & 0 & 0 & 0 \\
\hline Upset (6) & 0 & 0 & 0 & $\mathrm{O}$ & 0 & 0 & 0 & $\mathrm{O}$ & $\mathrm{O}$ \\
\hline Active (7) & $\mathrm{O}$ & $\mathrm{O}$ & 0 & $\mathrm{O}$ & $\mathrm{O}$ & 0 & $\bigcirc$ & $\mathrm{O}$ & $\mathrm{O}$ \\
\hline $\begin{array}{c}\text { Uncertain } \\
\text { (8) }\end{array}$ & O & 0 & 0 & O & 0 & 0 & 0 & 0 & $\mathrm{O}$ \\
\hline $\begin{array}{l}\text { Unexpected } \\
(9)\end{array}$ & 0 & 0 & 0 & $\mathrm{O}$ & $\mathrm{O}$ & 0 & $\mathrm{O}$ & $\mathrm{O}$ & $\mathrm{O}$ \\
\hline $\begin{array}{l}\text { Unsettled } \\
(10)\end{array}$ & $\mathrm{O}$ & 0 & $\mathrm{O}$ & $\mathrm{O}$ & 0 & 0 & $\mathrm{O}$ & $\mathrm{O}$ & $\mathrm{O}$ \\
\hline Jittery (11) & $\mathrm{O}$ & $\mathrm{O}$ & $\mathrm{O}$ & $\mathrm{O}$ & 0 & 0 & $\mathrm{O}$ & $\mathrm{O}$ & 0 \\
\hline $\begin{array}{l}\text { Excited } \\
\text { (12) }\end{array}$ & 0 & 0 & 0 & 0 & 0 & 0 & 0 & O & 0 \\
\hline Proud (13) & $\mathrm{O}$ & 0 & $\mathrm{O}$ & $\mathrm{O}$ & 0 & 0 & $\mathrm{O}$ & 0 & 0 \\
\hline $\begin{array}{c}\text { Interested } \\
(14)\end{array}$ & 0 & 0 & 0 & O & 0 & 0 & O & 0 & 0 \\
\hline $\begin{array}{c}\text { Enthusiastic } \\
\text { (15) }\end{array}$ & 0 & 0 & $\mathrm{O}$ & $\mathrm{O}$ & 0 & 0 & $\mathrm{O}$ & $\mathrm{O}$ & $\mathrm{O}$ \\
\hline Anxious & 0 & 0 & $\mathrm{O}$ & 0 & 0 & $\mathrm{O}$ & 0 & 0 & 0 \\
\hline
\end{tabular}




\begin{tabular}{|c|c|c|c|c|c|c|c|c|c|}
\hline $\begin{array}{c}(16) \\
\text { Surprised } \\
(17)\end{array}$ & 0 & 0 & 0 & 0 & 0 & 0 & 0 & 0 & 0 \\
$\begin{array}{c}\text { Scared (18) } \\
\text { Determined } \\
(19)\end{array}$ & 0 & 0 & 0 & 0 & 0 & 0 & 0 & 0 & 0 \\
$\begin{array}{c}\text { Attentive } \\
(20)\end{array}$ & 0 & 0 & 0 & 0 & 0 & 0 & 0 & 0 & 0 \\
\hline
\end{tabular}

4B B. The chair has been broken so it may collapse at any time during the experiment.

\begin{tabular}{|c|c|c|c|c|c|c|c|c|c|}
\hline & $I(1)$ & $2(2)$ & $3(3)$ & $4(4)$ & $5(5)$ & $6(6)$ & $7(7)$ & $8(8)$ & $9(9)$ \\
\hline $\begin{array}{c}\text { Ambiguous } \\
\text { (1) }\end{array}$ & 0 & 0 & 0 & 0 & $\mathrm{O}$ & 0 & 0 & 0 & 0 \\
\hline Inspired (2) & 0 & $\mathrm{O}$ & $\mathrm{O}$ & $\mathrm{O}$ & $\mathrm{O}$ & $\mathrm{O}$ & 0 & $\mathrm{O}$ & $\mathrm{O}$ \\
\hline Afraid (3) & 0 & 0 & 0 & 0 & $\mathrm{O}$ & 0 & 0 & 0 & 0 \\
\hline Hostile (4) & 0 & 0 & 0 & 0 & $\mathrm{O}$ & 0 & 0 & $\mathrm{O}$ & 0 \\
\hline Strong (5) & 0 & O & $\mathrm{O}$ & 0 & $\mathrm{O}$ & 0 & 0 & O & O \\
\hline Upset (6) & 0 & 0 & 0 & 0 & 0 & 0 & 0 & 0 & 0 \\
\hline Active (7) & 0 & O & 0 & 0 & $\mathrm{O}$ & 0 & 0 & 0 & $\mathrm{O}$ \\
\hline $\begin{array}{l}\text { Uncertain } \\
\quad(8)\end{array}$ & 0 & 0 & $\mathrm{O}$ & $\mathrm{O}$ & 0 & 0 & 0 & 0 & 0 \\
\hline $\begin{array}{l}\text { Unexpected } \\
\text { (9) }\end{array}$ & 0 & $\mathrm{O}$ & 0 & $\mathrm{O}$ & 0 & O & 0 & O & O \\
\hline $\begin{array}{l}\text { Unsettled } \\
\qquad(10)\end{array}$ & 0 & $\mathrm{O}$ & 0 & 0 & 0 & 0 & $\mathrm{O}$ & 0 & $\mathrm{O}$ \\
\hline Jittery (11) & 0 & 0 & 0 & 0 & 0 & 0 & 0 & O & $\mathrm{O}$ \\
\hline $\begin{array}{c}\text { Excited } \\
(12)\end{array}$ & O & $\mathrm{O}$ & 0 & $\mathrm{O}$ & 0 & 0 & 0 & 0 & 0 \\
\hline Proud (13) & 0 & 0 & 0 & $\mathrm{O}$ & 0 & 0 & O & 0 & $\mathrm{O}$ \\
\hline $\begin{array}{l}\text { Interested } \\
\text { (14) }\end{array}$ & O & 0 & 0 & O & 0 & 0 & O & 0 & $\mathrm{O}$ \\
\hline $\begin{array}{l}\text { Enthusiastic } \\
\text { (15) }\end{array}$ & 0 & 0 & $\mathrm{O}$ & $\mathrm{O}$ & 0 & 0 & 0 & 0 & 0 \\
\hline Anxious & 0 & 0 & 0 & 0 & 0 & 0 & 0 & 0 & 0 \\
\hline
\end{tabular}




\begin{tabular}{|c|c|c|c|c|c|c|c|c|c|}
\hline $\begin{array}{c}(16) \\
\text { Surprised } \\
(17)\end{array}$ & 0 & 0 & 0 & 0 & 0 & 0 & 0 & 0 & 0 \\
$\begin{array}{c}\text { Scared (18) } \\
\text { Determined } \\
(19)\end{array}$ & 0 & 0 & 0 & 0 & 0 & 0 & 0 & 0 & 0 \\
$\begin{array}{c}\text { Attentive } \\
(20)\end{array}$ & 0 & 0 & 0 & 0 & 0 & 0 & 0 & 0 & 0 \\
\hline
\end{tabular}

5 Context. A research assistant will be observing your performance in the room as a judge. You will be told one of the following instructions:

$5 \mathrm{~A} \mathrm{~A}$. The judge tells you that he has been assisting the experiment for over a semester, so he makes sure that nothing goes wrong during the game.

\begin{tabular}{|c|c|c|c|c|c|c|c|c|c|}
\hline & $1(1)$ & $2(2)$ & $3(3)$ & $4(4)$ & $5(5)$ & $6(6)$ & $7(7)$ & $8(8)$ & $9(9)$ \\
\hline $\begin{array}{l}\text { Ambiguous } \\
\text { (1) }\end{array}$ & 0 & 0 & 0 & 0 & $\mathrm{O}$ & $\mathrm{O}$ & 0 & 0 & 0 \\
\hline Inspired (2) & 0 & 0 & 0 & 0 & 0 & 0 & 0 & 0 & $O$ \\
\hline Afraid (3) & 0 & 0 & 0 & O & O & 0 & 0 & 0 & 0 \\
\hline Hostile (4) & 0 & 0 & 0 & 0 & 0 & 0 & 0 & 0 & 0 \\
\hline Strong (5) & 0 & 0 & 0 & 0 & 0 & 0 & 0 & 0 & 0 \\
\hline Upset (6) & 0 & 0 & 0 & 0 & 0 & 0 & $\mathrm{O}$ & $\mathrm{O}$ & $O$ \\
\hline Active (7) & 0 & 0 & 0 & 0 & 0 & 0 & 0 & 0 & 0 \\
\hline $\begin{array}{l}\text { Uncertain } \\
(8)\end{array}$ & 0 & O & 0 & O & O & o & 0 & 0 & 0 \\
\hline $\begin{array}{l}\text { Unexpected } \\
\text { (9) }\end{array}$ & 0 & O & 0 & O & O & O & 0 & 0 & 0 \\
\hline $\begin{array}{l}\text { Unsettled } \\
(10)\end{array}$ & 0 & 0 & 0 & 0 & $\mathrm{O}$ & $\mathrm{O}$ & 0 & 0 & 0 \\
\hline Jittery (11) & 0 & $\mathrm{O}$ & 0 & 0 & $\mathrm{O}$ & 0 & 0 & 0 & 0 \\
\hline $\begin{array}{l}\text { Excited } \\
\text { (12) }\end{array}$ & 0 & 0 & 0 & 0 & 0 & 0 & 0 & 0 & 0 \\
\hline Proud (13) & 0 & 0 & 0 & 0 & 0 & $\mathrm{O}$ & $\mathrm{O}$ & $\mathrm{O}$ & $\mathrm{O}$ \\
\hline Interested & 0 & O & $\mathrm{O}$ & 0 & $\mathrm{O}$ & 0 & 0 & 0 & 0 \\
\hline
\end{tabular}




\begin{tabular}{|c|c|c|c|c|c|c|c|c|c|}
\hline $\begin{array}{c}(14) \\
\text { Enthusiastic } \\
(15)\end{array}$ & 0 & 0 & 0 & 0 & 0 & 0 & 0 & 0 & 0 \\
$\begin{array}{c}\text { Anxious } \\
(16)\end{array}$ & 0 & 0 & 0 & 0 & 0 & 0 & 0 & 0 & 0 \\
$\begin{array}{c}\text { Surprised } \\
(17)\end{array}$ & 0 & 0 & 0 & 0 & 0 & 0 & 0 & 0 & 0 \\
$\begin{array}{c}\text { Scared (18) } \\
\text { Determined } \\
(19)\end{array}$ & 0 & 0 & 0 & 0 & 0 & 0 & 0 & 0 & 0 \\
Attentive \\
$(20)$
\end{tabular}

5B B. You will be told that the experimenter has just been hired recently, so he may not be fully used to the procedure.

\begin{tabular}{|c|c|c|c|c|c|c|c|c|c|}
\hline Ambiguous & $1(1)$ & $2(2)$ & $3(3)$ & $4(4)$ & $5(5)$ & $6(6)$ & $7(7)$ & $8(8)$ & $9(9)$ \\
$\quad$ (1) & 0 & 0 & 0 & 0 & 0 & 0 & 0 & 0 & 0 \\
Inspired (2) & 0 & 0 & 0 & 0 & 0 & 0 & 0 & 0 & 0 \\
Afraid (3) & 0 & 0 & 0 & 0 & 0 & 0 & 0 & 0 & 0 \\
Hostile (4) & 0 & 0 & 0 & 0 & 0 & 0 & 0 & 0 & 0 \\
Strong (5) & 0 & 0 & 0 & 0 & 0 & 0 & 0 & 0 & 0 \\
Upset (6) & 0 & 0 & 0 & 0 & 0 & 0 & 0 & 0 & 0 \\
Active (7) & 0 & 0 & 0 & 0 & 0 & 0 & 0 & 0 & 0 \\
Uncertain & 0 & 0 & 0 & 0 & 0 & 0 & 0 & 0 & 0 \\
$\quad$ (8) & 0 & 0 & 0 & 0 & 0 & 0 & 0 & 0 & 0 \\
Unexpected & 0 & 0 & 0 & 0 & 0 & 0 & 0 & 0 & 0 \\
$\quad$ (9) & 0 & 0 & 0 & 0 & 0 & 0 & 0 \\
Unsettled & 0 & 0 & 0 & 0 & 0 & 0 & 0 & 0 & 0 \\
Jittery (11) & 0 & 0 & 0 & 0 & 0 & 0 & 0 \\
Excited & 0 & 0 & 0 & 0 & 0 & 0 & 0 & 0 \\
$\quad(12)$ & 0 & 0 & 0 & 0 & 0 & 0 & 0 & 0 & 0 \\
Proud (13) & 0 & 0 &
\end{tabular}




\begin{tabular}{|c|c|c|c|c|c|c|c|c|c|}
\hline $\begin{array}{c}\text { Interested } \\
(14)\end{array}$ & 0 & 0 & 0 & 0 & 0 & 0 & 0 & 0 & 0 \\
$\begin{array}{c}\text { Enthusiastic } \\
(15)\end{array}$ & 0 & 0 & 0 & 0 & 0 & 0 & 0 & 0 & 0 \\
$\begin{array}{c}\text { Anxious } \\
(16)\end{array}$ & 0 & 0 & 0 & 0 & 0 & 0 & 0 & 0 & 0 \\
$\begin{array}{c}\text { Surprised } \\
(17)\end{array}$ & 0 & 0 & 0 & 0 & 0 & 0 & 0 & 0 & 0 \\
$\begin{array}{c}\text { Scared (18) } \\
\text { Determined } \\
(19)\end{array}$ & 0 & 0 & 0 & 0 & 0 & 0 & 0 & 0 & 0 \\
Attentive & 0 & 0 & 0 & 0 & 0 & 0 & 0 & 0 & 0 \\
\hline
\end{tabular}

6 Context. An experimenter will give you one of the following instructions:

$6 \mathrm{~A} \mathrm{~A}$. At the beginning of the game the experimenter ensures that the game will be played for 20 trials.

\begin{tabular}{|c|c|c|c|c|c|c|c|c|c|}
\hline Ambiguous & $1(1)$ & $2(2)$ & $3(3)$ & $4(4)$ & $5(5)$ & $6(6)$ & $7(7)$ & $8(8)$ & $9(9)$ \\
$(1)$ & 0 & 0 & 0 & 0 & 0 & 0 & 0 & 0 & 0 \\
Inspired (2) & 0 & 0 & 0 & 0 & 0 & 0 & 0 & 0 & 0 \\
Afraid (3) & 0 & 0 & 0 & 0 & 0 & 0 & 0 & 0 & 0 \\
Hostile (4) & 0 & 0 & 0 & 0 & 0 & 0 & 0 & 0 & 0 \\
Strong (5) & 0 & 0 & 0 & 0 & 0 & 0 & 0 & 0 & 0 \\
Upset (6) & 0 & 0 & 0 & 0 & 0 & 0 & 0 & 0 & 0 \\
Active (7) & 0 & 0 & 0 & 0 & 0 & 0 & 0 & 0 & 0 \\
Uncertain & 0 & 0 & 0 & 0 & 0 & 0 & 0 & 0 & 0 \\
$(8)$ & 0 & 0 & 0 & 0 & 0 & 0 & 0 \\
Unexpected & 0 & 0 & 0 & 0 & 0 & 0 & 0 & 0 & 0 \\
(9) & 0 & 0 & 0 & 0 & 0 & 0 & 0 \\
Unsettled & 0 & 0 & 0 & 0 & 0 & 0 & 0 & 0 \\
Jittery (11) & 0 & 0 & 0 & 0 & 0 & 0
\end{tabular}




\begin{tabular}{|c|c|c|c|c|c|c|c|c|c|}
\hline $\begin{array}{c}\text { Excited } \\
(12)\end{array}$ & 0 & 0 & 0 & 0 & 0 & 0 & 0 & 0 & 0 \\
$\begin{array}{c}\text { Proud (13) } \\
\text { Interested } \\
(14)\end{array}$ & 0 & 0 & 0 & 0 & 0 & 0 & 0 & 0 & 0 \\
$\begin{array}{c}\text { Enthusiastic } \\
(15)\end{array}$ & 0 & 0 & 0 & 0 & 0 & 0 & 0 & 0 & 0 \\
$\begin{array}{c}\text { Anxious } \\
(16)\end{array}$ & 0 & 0 & 0 & 0 & 0 & 0 & 0 & 0 & 0 \\
$\begin{array}{c}\text { Surprised } \\
(17)\end{array}$ & 0 & 0 & 0 & 0 & 0 & 0 & 0 & 0 & 0 \\
$\begin{array}{c}\text { Scared (18) } \\
\text { Determined } \\
(19)\end{array}$ & 0 & 0 & 0 & 0 & 0 & 0 & 0 & 0 & 0 \\
Attentive & 0 & 0 & 0 & 0 & 0 & 0 & 0 & 0 & 0 \\
\hline (20)
\end{tabular}

6B B. At the beginning of the game the experimenter reminds you and your partner that you are not supposed to know how many trials you will play, and the game might end at any time.

\begin{tabular}{|c|l|l|l|l|l|l|l|l|l|}
\hline & $1(1)$ & $2(2)$ & $3(3)$ & $4(4)$ & $5(5)$ & $6(6)$ & $7(7)$ & $8(8)$ & $9(9)$ \\
\hline Ambiguous & 0 & 0 & 0 & 0 & 0 & 0 & 0 & 0 & 0 \\
(1) & 0 & 0 & 0 & 0 & 0 & 0 & 0 & 0 & 0 \\
Inspired (2) & 0 & 0 & 0 & 0 & 0 & 0 & 0 & 0 & 0 \\
Afraid (3) & 0 & 0 & 0 & 0 & 0 & 0 & 0 & 0 & 0 \\
Hostile (4) & 0 & 0 & 0 & 0 & 0 & 0 & 0 \\
Strong (5) & 0 & 0 & 0 & 0 & 0 & 0 & 0 & 0 \\
Upset (6) & 0 & 0 & 0 & 0 & 0 & 0 & 0 & 0 & 0 \\
Active (7) & 0 & 0 & 0 & 0 & 0 & 0 & 0 & 0 & 0 \\
Uncertain & 0 & 0 & 0 & 0 & 0 & 0 & 0 & 0 & 0 \\
(8) & 0 & & 0 & 0 & 0 & 0 & 0 & 0 & 0 \\
Unexpected & 0 & 0 & 0 & 0 & 0 & 0 & 0 & 0 & 0 \\
(9) & 0 & 0 & 0 & 0 & 0 & \\
Unsettled & 0 & 0 & & & & & & \\
\hline
\end{tabular}




\begin{tabular}{|c|c|c|c|c|c|c|c|c|c|}
\hline (10) & & & & & & & & & \\
\hline Jittery (11) & 0 & 0 & 0 & 0 & 0 & 0 & O & 0 & 0 \\
\hline $\begin{array}{l}\text { Excited } \\
\text { (12) }\end{array}$ & 0 & 0 & 0 & 0 & 0 & 0 & O & 0 & 0 \\
\hline Proud (13) & 0 & 0 & O & 0 & O & 0 & 0 & $\mathrm{O}$ & $\mathrm{O}$ \\
\hline $\begin{array}{l}\text { Interested } \\
\text { (14) }\end{array}$ & 0 & 0 & 0 & 0 & 0 & 0 & 0 & 0 & O \\
\hline $\begin{array}{c}\text { Enthusiastic } \\
\text { (15) }\end{array}$ & 0 & 0 & 0 & 0 & 0 & 0 & 0 & 0 & 0 \\
\hline $\begin{array}{c}\text { Anxious } \\
(16)\end{array}$ & O & O & 0 & 0 & 0 & 0 & 0 & 0 & 0 \\
\hline $\begin{array}{l}\text { Surprised } \\
\text { (17) }\end{array}$ & 0 & 0 & 0 & 0 & 0 & 0 & 0 & 0 & 0 \\
\hline Scared (18) & 0 & $\mathrm{O}$ & O & 0 & $\mathrm{O}$ & 0 & 0 & 0 & 0 \\
\hline $\begin{array}{l}\text { Determined } \\
\text { (19) }\end{array}$ & 0 & 0 & 0 & 0 & 0 & 0 & 0 & 0 & 0 \\
\hline $\begin{array}{c}\text { Attentive } \\
\text { (20) }\end{array}$ & 0 & O & 0 & 0 & O & 0 & 0 & 0 & 0 \\
\hline
\end{tabular}

7 Context. Your performance on the task is dependent on a computer that you will use. The computer will be in one of the following contexts:

7A A. The computer has been replaced with a new one, so you should not worry about any technical problems during the experiment.

\begin{tabular}{|c|c|c|c|c|c|c|c|c|c|}
\hline & $1(1)$ & $2(2)$ & $3(3)$ & $4(4)$ & $5(5)$ & $6(6)$ & $7(7)$ & $8(8)$ & $9(9)$ \\
\hline Ambiguous & 0 & 0 & 0 & 0 & 0 & 0 & 0 & 0 & 0 \\
$\quad(1)$ & & 0 & 0 & 0 & 0 & 0 & 0 & 0 & 0 \\
Inspired (2) & 0 & 0 & 0 & 0 & 0 & 0 & 0 & 0 & 0 \\
Afraid (3) & 0 & 0 & 0 & 0 & 0 & 0 & 0 & 0 & 0 \\
Hostile (4) & 0 & 0 & 0 & 0 & 0 & 0 & 0 & 0 & 0 \\
Strong (5) & 0 & 0 & 0 & 0 & 0 & 0 & 0 \\
Upset (6) & 0 & 0 & 0 & 0 & 0 & 0 & 0 & 0 & 0 \\
Active (7) & 0 & 0 & 0 & 0 & 0 & 0 & 0 & 0 & 0 \\
Uncertain & 0 & 0 & 0 & 0 & 0 & 0 & 0 & 0 & 0 \\
(8) & 0 & 0 & 0 & 0 & 0 & 0 & 0 & 0 & 0 \\
Unexpected & 0 & 0 \\
\hline
\end{tabular}




\begin{tabular}{|c|c|c|c|c|c|c|c|c|c|}
\hline (9) & & & & & & & & & \\
\hline $\begin{array}{l}\text { Unsettled } \\
\text { (10) }\end{array}$ & 0 & 0 & 0 & 0 & 0 & 0 & 0 & 0 & O \\
\hline Jittery (11) & 0 & O & 0 & 0 & 0 & 0 & 0 & 0 & 0 \\
\hline $\begin{array}{l}\text { Excited } \\
\text { (12) }\end{array}$ & 0 & O & 0 & O & 0 & 0 & 0 & O & O \\
\hline Proud (13) & 0 & O & 0 & 0 & 0 & 0 & 0 & O & 0 \\
\hline $\begin{array}{l}\text { Interested } \\
\text { (14) }\end{array}$ & 0 & 0 & 0 & 0 & 0 & 0 & 0 & 0 & 0 \\
\hline $\begin{array}{l}\text { Enthusiastic } \\
\text { (15) }\end{array}$ & 0 & 0 & 0 & 0 & 0 & O & 0 & O & 0 \\
\hline $\begin{array}{l}\text { Anxious } \\
(16)\end{array}$ & 0 & O & 0 & 0 & 0 & O & 0 & 0 & 0 \\
\hline $\begin{array}{l}\text { Surprised } \\
\text { (17) }\end{array}$ & 0 & 0 & 0 & 0 & 0 & O & 0 & 0 & 0 \\
\hline Scared (18) & 0 & 0 & 0 & O & 0 & 0 & 0 & O & O \\
\hline $\begin{array}{l}\text { Determined } \\
\text { (19) }\end{array}$ & $\mathrm{O}$ & $\mathrm{O}$ & 0 & 0 & 0 & O & 0 & O & O \\
\hline $\begin{array}{l}\text { Attentive } \\
\text { (20) }\end{array}$ & 0 & 0 & 0 & 0 & 0 & 0 & 0 & 0 & 0 \\
\hline
\end{tabular}

7B B. While you are filling out the demographics, one of the computers you or your partner is working on shuts down. You will be told that the experimenter does not have a replacement so you/your partner have to continue to work on the entire experiment on the same computer.

\begin{tabular}{|c|c|c|c|c|c|c|c|c|c|}
\hline & $1(1)$ & $2(2)$ & $3(3)$ & $4(4)$ & $5(5)$ & $6(6)$ & $7(7)$ & $8(8)$ & $9(9)$ \\
\hline $\begin{array}{c}\text { Ambiguous } \\
\text { (1) }\end{array}$ & 0 & 0 & 0 & 0 & 0 & 0 & 0 & 0 & 0 \\
Inspired (2) & 0 & 0 & 0 & 0 & 0 & 0 & 0 & 0 & 0 \\
Afraid (3) & 0 & 0 & 0 & 0 & 0 & 0 & 0 & 0 & 0 \\
Hostile (4) & 0 & 0 & 0 & 0 & 0 & 0 & 0 & 0 & 0 \\
Strong (5) & 0 & 0 & 0 & 0 & 0 & 0 & 0 & 0 & 0 \\
Upset (6) & 0 & 0 & 0 & 0 & 0 & 0 & 0 & 0 & 0 \\
Active (7) & 0 & 0 & 0 & 0 & 0 & 0 & 0 & 0 & 0 \\
\hline
\end{tabular}




\begin{tabular}{|c|c|c|c|c|c|c|c|c|c|}
\hline $\begin{array}{l}\text { Uncertain } \\
\text { (8) }\end{array}$ & 0 & 0 & 0 & 0 & O & 0 & O & $\mathrm{O}$ & 0 \\
\hline $\begin{array}{l}\text { Unexpected } \\
\text { (9) }\end{array}$ & 0 & 0 & 0 & 0 & 0 & 0 & 0 & 0 & 0 \\
\hline $\begin{array}{l}\text { Unsettled } \\
\text { (10) }\end{array}$ & 0 & $\mathrm{O}$ & 0 & 0 & $\mathrm{O}$ & 0 & 0 & 0 & $\mathrm{O}$ \\
\hline Jittery (11) & 0 & 0 & 0 & 0 & 0 & 0 & 0 & 0 & 0 \\
\hline $\begin{array}{l}\text { Excited } \\
\text { (12) }\end{array}$ & 0 & $\mathrm{O}$ & 0 & 0 & 0 & 0 & 0 & O & 0 \\
\hline Proud (13) & 0 & 0 & 0 & 0 & 0 & 0 & 0 & 0 & $\mathrm{O}$ \\
\hline $\begin{array}{l}\text { Interested } \\
\text { (14) }\end{array}$ & 0 & 0 & 0 & 0 & 0 & 0 & 0 & 0 & $\mathrm{O}$ \\
\hline $\begin{array}{c}\text { Enthusiastic } \\
\text { (15) }\end{array}$ & 0 & 0 & 0 & 0 & 0 & 0 & 0 & 0 & 0 \\
\hline $\begin{array}{l}\text { Anxious } \\
(16)\end{array}$ & 0 & O & 0 & 0 & O & 0 & $\mathrm{O}$ & 0 & 0 \\
\hline $\begin{array}{l}\text { Surprised } \\
\text { (17) }\end{array}$ & 0 & 0 & 0 & 0 & 0 & $O$ & $\mathrm{O}$ & $O$ & $\mathrm{O}$ \\
\hline Scared (18) & 0 & $\mathrm{O}$ & 0 & 0 & 0 & 0 & 0 & 0 & 0 \\
\hline $\begin{array}{l}\text { Determined } \\
\text { (19) }\end{array}$ & 0 & 0 & 0 & 0 & 0 & 0 & 0 & 0 & 0 \\
\hline $\begin{array}{l}\text { Attentive } \\
\text { (20) }\end{array}$ & 0 & 0 & 0 & 0 & 0 & 0 & 0 & 0 & 0 \\
\hline
\end{tabular}




\section{Debrief Debriefing Section}

The purpose of the survey was to investigate what contexts elicit feelings associated with uncertainty. The target feelings the investigator was interested in were: surprised, unexpected, uncertain, unsetteled, anxious, upset, jittery, ambiguous, scared, and afraid. The other words were distracters. Your response will be used to determine which descriptions scored the higest uncertainty. The descriptions that scored higher uncerainty will be used as a uncertainty manipulation in a future study.

Q44 To compete the survey, please click the arrow in the bottom right corner. 
Appendix B

San Francisco State University

Consent to Participate in Research

Values and Decision-Making

Purpose: The purpose of this study is to examine how values are related to decisionmaking. The principal investigator, Kodai Kusano, is a master's student in the Psychology Department at San Francisco State University. His advisor, David Matsumoto, is a Professor in the Psychology Department at San Francisco State University. YOU MUST BE 18 or OLDER TO PARTICIPATE.

Procedures: The study consists of the following 4 phases:

1. A packet of 3 questionnaires.

2. A decision-making game - You will play a simple bargaining game with another person in a separate room. The two of you will both play roles of Proposer and Responder. In each trial, both players have to distribute a given amount, $\$ 5$ among themselves. First, the Proposer will be given $\$ 5$. He/she can determine how much of $\$ 5$ he/she keeps for him/herself. The remaining will be offered to the Responder. Knowing the Proposer's offer, the Responder has to either accept or reject this offer. If the Responder accepts the Proposer's offer, both get the money as proposed. In case of rejection, both get zero. All transactions will be performed over computers, so your decision will be anonymous. Your 
compensation for participating in this study will depend upon the total amount of money you earned in the game. The final outcome will range from $\$ 0$ to $\$ 10$.

3. A follow-up questionnaire.

4. Debriefing

Duration: It takes approximately 40 to 50 minutes to complete the entire study.

Risks: There is a risk of loss of privacy. However, no names or identities will be used in any published reports of the research. All research data will be stored in an encrypted document on a password-protected computer.

Confidentiality: All of your responses will be confidential. Your informed consent will be kept in a locked cabinet in the room EP329. All research data will be stored in a device with full disk encryption and password-protection. The data will be kept for a period of three years, after which it will be destroyed. More information can be found at the following website http://tech.sfsu.edu/policy/confidential-data and/or you may contact DoIT at 415-338-1420.

Direct Benefits: There will be no direct benefits to the participant.

Costs: There will be no cost to you for participating in this research.

Compensation: You will receive financial compensation. The final outcome of the compensation, however, will depend on how you interact with your partner during the decision-making game. That is, your compensation may decrease or increase depending on how you and your partner play the game. The financial compensation ranges from $\$ 0$ to $\$ 10$. 
Alternatives: The alternative is not to participate in the research.

Voluntary Participation: You are free to decline to participate in this research study, or to withdraw your participation at any point. However, you must complete the study to receive the compensation.

Questions: Questions about your rights as a study participant, or comments or complaints about the study, may also be addressed to the Office for the Protection of Human Subjects at 415: 338-1093 or protocol@sfsu.edu

Any questions or concerns should be directed to the principal investigator, Kodai Kusano by email at kusano@mail.sfsu.edu or the research advisor, Professor David Matsumoto at dm@sfsu.edu. Your status at SFSU will not be affected.

Are you 18 years of age or older?

- Yes

No

Do you agree to participate in the study?

Yes Signature:

No 


\section{Appendix C}

\section{I}

This questionnaire is anonymous, and there are no right or wrong answers. We want to know if you strongly agree or disagree with some statements. If you strongly agree, enter a 9 in the blank space; if you strongly disagree, enter a 1 in that space; if you are unsure, enter a 5 next to the statement. In short, use this key:

Strongly

Disagree

1
Unsure

4
$5 \quad 6$
Strongly

Agree

1. I prefer to be direct and forthright when I talk with people.

2. My happiness depends very much on the happiness of those around me.

3. I would do what would please my family, even if I detested that activity.

4. Winning is everything.

5. One should live one's life independently of others.

6. What happens to me is my own doing.

7. I usually sacrifice my self-interest for the benefit of my group.

8. It annoys me when other people perform better than I do.

9. It is important for me to maintain harmony within my group.

10. It is important to me that I do my job better than others.

11. I like sharing little things with my neighbors.

12. I enjoy working in situations involving competition with others.

13. We should keep our aging parents with us at home.

14. The well-being of my co-workers is important to me. 
15. I enjoy being unique and different from others in many ways.

16. If a relative were in financial difficulty, I would help within my means.

17. Children should feel honored if their parents receive a distinguished award.

18. I often do "my own thing."

19. Competition is the law of nature.

20. If a co-worker gets a prize I would feel proud.

21. I am a unique individual.

22. To me, pleasure is spending time with others.

23. When another person does better than I do, I get tense and aroused.

24. I would sacrifice an activity that I enjoy very much if my family did not approve of it.

25. I like my privacy.

26. Without competition it is not possible to have a good society.

27. Children should be taught to place duty before pleasure.

28. I feel good when I cooperate with others.

29. I hate to disagree with others in my group.

30. Some people emphasize winning; I am not one of them.

31. Before taking a major trip, I consult with most members of my family and many friends.

32. When I succeed, it is usually because of my abilities. 
This questionnaire contains 12 statements. Read each statement carefully. For each statement, please enter the response in the blank space that best represents your opinion according to the following 5-point scale:

$\begin{array}{lllll}\begin{array}{l}\text { Strongly } \\ \text { Disagree }\end{array} & \text { Disagree } & \text { Neutral } & \text { Agree } & \text { Strongly Agree } \\ 1 & 2 & 3 & 4 & 5\end{array}$

1. I am not a worrier.

2. At times I have felt bitter and resentful.

3. When I'm under a great deal of stress, sometimes I feel like I'm going to pieces.

4. I rarely feel lonely or blue.

5. I often feel tense and jittery.

6. Sometimes I feel completely worthless.

7. I rarely feel fearful or anxious.

8. I often get angry at the way people treat me.

9. Too often, when things go wrong, I get discouraged and feel like giving up.

10. I am seldom sad or depressed.

11. I often feel helpless and want someone else to solve my problems.

12. At times I have been so ashamed I just want to hide. 


\section{III}

Please read each of the following statements and decide how much each statement describes your characteristics according to your attitudes, beliefs, and experiences. This questionnaire is anonymous, and there are no right or wrong answers. Please respond in the blank space according to the following 5-point scale:

Not at all characteristic of me

Neutral

1
Extremely characteristic of me

1. Uncertainty stops me from having a strong opinion.

2. Being uncertain means that a person is disorganized.

3. Uncertainty makes life intolerable.

4. It's unfair having no guarantees in life.

5. My mind can't be relaxed if I don't know what will happen tomorrow.

6. Uncertainty makes me uneasy, anxious, or stressed.

7. Unforeseen events upset me greatly.

8. It frustrates me not having all the information I need.

9. Uncertainty keeps me from living a full life.

10. One should always look ahead so as to avoid surprises.

11. A small unforeseen event can spoil everything, even with the best planning. 
12. When it's time to eat, uncertainty paralyses me.

13. Being uncertain means that I am not first rate.

14. When I am uncertain, I can't go forward.

Not at all

characteristic of

me

1
2
Neutral

3
Extremely characteristic of me

15. When I am uncertain, I can't function very well.

16. Unlike me, others seem to know where they are going with their lives.

17. Uncertainty makes me vulnerable, unhappy, or sad.

18. I always want to know what the future has in store for me.

19. I can't stand being taken by surprise.

20. The smallest doubt can stop me from acting.

21. I should be able to organize everything in advance.

22. Being uncertain means that I lack confidence.

23. I think it's unfair that other people seem to be sure about their future.

24. Uncertainty keeps me from sleeping soundly.

25. I must get away from all uncertain situations.

26. The ambiguities in life stress me.

27. I can't stand being undecided about my future. 


\section{Appendix D}

Using a mouse, please click the "Proceed" button on the bottom right corner of the screen to start the instructions.

For each set of instructions, please take as much time as you need to make sure that you understand the instructions before continuing to the next page.

$\underline{\text { Start }}$

\section{Instructions $(1 / 5)$}

You will play a simple bargaining game with another participant in a separate room.

All transactions will be done over the computer, and you won't meet the other player, so your decisions will be anonymous.

There will be two trials in the study. For each trial, you will be assigned to one of two roles; either "Proposer" or "Responder."

If you have any questions or concerns about these instructions, please ring the bell to call the experimenter for some assistance. Otherwise please continue by

$$
\text { clicking "Proceed" }
$$




\section{Instructions $(2 / 5)$}

In the first trial of the study, you will be randomly assigned to either the role of

"Proposer" or the role of "Responder."

In the second trial, the roles will be switched.

In each trial of the study, the Proposer's job will be to decide how to distribute a given amount of money between the participants.

The Proposer will be given $\$ 5$. He/she can decide how much money to keep for him/herself and how much to give to the other player. This can be any amount, in dollars and cents, from $\$ 0$ to $\$ 5$.

The remainder will be offered to the Responder, who can decide whether to accept or reject the offer.

If the Responder accepts, both players get the amount agreed upon.

If the Responder chooses to reject, however, both players get $\$ 0$.

If you have any questions or concerns about these instructions, please ring the bell to call the experimenter for some assistance. Otherwise please continue by clicking "Proceed"

Proceed

\section{Instructions (3/5)}

Now let's go over an example.

Suppose that the Proposer decides to keep $\$ 2.80$ for him/herself. 
This means that the Responder will then be offered the remaining $\$ 2.20$.

If the Responder accepts this offer, the Proposer gets to keep the $\$ 2.80$, and the

Responder gets to keep $\$ 2.20$.

If the Responder rejects this offer, both players get $\$ 0$.

If you have any questions or concerns about these instructions, please ring the bell to call the experimenter for some assistance. Otherwise please continue by clicking "Proceed"

Instructions (4/5)

Your total compensation in this study is the sum of the money you received from each trial.

Therefore, it is very important for you to recognize that the more money you have at the end, the more compensation you will get for participating in this study.

If you have any questions or concerns about these instructions, please ring the bell to call the experimenter for some assistance. Otherwise please continue by clicking "Proceed"

Proceed

\section{Instructions (5/5)}

Are you ready to begin the game? 
If you have any questions, please ring the bell and we will be happy to answer them now.

After this point, you can no longer ask questions or speak with the experimenter.

If you are ready to continue, please start the game by clicking "Begin"

Begin

\section{Additional Instruction (Certain)}

There will be 2 trials.

You have been randomly assigned to be a Proposer in the first trial. This means you will be a Responder in the second trial.

The experimental protocol at the university requires us to inform you of the following information regarding equipments:

The chair on which you are sitting has recently been replaced with a new one for this experiment.

The alarm on the table has been functioning well.

Proceed

\section{Additional Instruction (Uncertain)}

Actually, the number of trials in the game will be randomly determined. Your compensation will be the average of the amount of money earned across all trials.

You can play the game until the computer instructs you to stop. 
The experimental protocol at the university requires us to inform you of the following information regarding equipments:

The chair on which you are sitting has been broken. We've tried our best to fix it, but it may collapse at any time during the game.

The alarm on the table will randomly go off to indicate the end of the game.

Proceed

You will be a Proposer in the first trial.

Please click "OK" to continue.

OK

You are a Proposer.

The amount of money distributed:

Please enter the amount of money you would like to keep for yourself:

(The remainder will be offered to the other player.)

Please click "OK" to continue.

OK

Please wait until your partner's decision is made. 
The amount of money distributed:

Your offer to your partner:

This offer was: Accepted

Your income in this trial:

Your partner's income in this trial:

Click "OK" to continue.

OK

You will be a Responder in the second trial.

Please click "OK" to continue.

OK

You are a Responder in this trial.

Please wait until your partner's decision is made.

The amount of money distributed:

The amount of money offered to you:

Do you accept or reject this offer?

Please click "OK" to continue. 
Your partner's offer to you:

Your decision:

Your income in this trial:

Your partner's income in this trial:

Click "OK" to continue.

This section displays the total amount of money you and your partner earned from the two trials.

Your total money from the two trials:

Your partner's total money from the two trials:

Please click "OK" to confirm

You have successfully completed the game!

Please click the "Finish" button and ring the bell to call the experimenter.

Finish 


\section{Appendix E}

We would like to ask you how you felt during the game. Please evaluate to what extent you felt the following feelings by circling an appropriate number for each feeling.

$1($ Not at all $)=$ "didn't evoke the feeling at all"

$5($ Moderate $)=$ "evoked moderate amount of the feeling"

$9($ Extremely $)=$ "evoked extreme amount of the feeling"

\begin{tabular}{|c|c|c|c|c|c|c|c|c|c|c|}
\hline & \multicolumn{3}{|c|}{ Not at all } & \multicolumn{5}{|c|}{ Moderate } & \multicolumn{2}{|c|}{ Extremely } \\
\hline 1. & Ambiguous & 1 & 2 & 3 & 4 & 5 & 6 & 7 & 8 & 9 \\
\hline 2. & Inspired & 1 & 2 & 3 & 4 & 5 & 6 & 7 & 8 & 9 \\
\hline 3. & Afraid & 1 & 2 & 3 & 4 & 5 & 6 & 7 & 8 & 9 \\
\hline 4. & Hostile & 1 & 2 & 3 & 4 & 5 & 6 & 7 & 8 & 9 \\
\hline 5. & Strong & 1 & 2 & 3 & 4 & 5 & 6 & 7 & 8 & 9 \\
\hline 6. & Upset & 1 & 2 & 3 & 4 & 5 & 6 & 7 & 8 & 9 \\
\hline 7. & Active & 1 & 2 & 3 & 4 & 5 & 6 & 7 & 8 & 9 \\
\hline 8. & Uncertain & 1 & 2 & 3 & 4 & 5 & 6 & 7 & 8 & 9 \\
\hline 9. & Unexpected & 1 & 2 & 3 & 4 & 5 & 6 & 7 & 8 & 9 \\
\hline 10. & Unsettled & 1 & 2 & 3 & 4 & 5 & 6 & 7 & 8 & 9 \\
\hline 11. & Jittery & 1 & 2 & 3 & 4 & 5 & 6 & 7 & 8 & 9 \\
\hline 12. & Excited & 1 & 2 & 3 & 4 & 5 & 6 & 7 & 8 & 9 \\
\hline 13. & Proud & 1 & 2 & 3 & 4 & 5 & 6 & 7 & 8 & 9 \\
\hline 14. & Interested & 1 & 2 & 3 & 4 & 5 & 6 & 7 & 8 & 9 \\
\hline 15. & Enthusiastic & 1 & 2 & 3 & 4 & 5 & 6 & 7 & 8 & 9 \\
\hline 16. & Anxious & 1 & 2 & 3 & 4 & 5 & 6 & 7 & 8 & 9 \\
\hline 17. & Surprised & 1 & 2 & 3 & 4 & 5 & 6 & 7 & 8 & 9 \\
\hline 18. & Scared & 1 & 2 & 3 & 4 & 5 & 6 & 7 & 8 & 9 \\
\hline 19. & Determined & 1 & 2 & 3 & 4 & 5 & 6 & 7 & 8 & 9 \\
\hline 20. & Attentive & 1 & 2 & 3 & 4 & 5 & 6 & 7 & 8 & 9 \\
\hline
\end{tabular}


We would like to ask you some background information. If you are unsure or do not want to answer, feel free to leave it blank.

Gender:

Age:

Nationality: Type of Visa (if you are an international student):

Class year (circle one): first year sophomore junior senior graduate student (others):

Major Course of Study:

First Language: Second Language:

Ethnicity (please circle):

White/Caucasian

African American

Hispanic

Asian

Multi-ethnic (please specify)

Other (please specify) with ancestors from the country of

Religious Status:

From the time you were born until now, what countries have you lived in?

Age

Country

0 to 
to

to

This is the end of the study. Please ring the bell to call the experimenter. 


\section{Appendix F}

\section{Debriefing Script}

The true purpose of the study was to examine how uncertain contexts influenced cooperative behavior. In this study, the cooperative behavior was defined as the willingness to sacrifice your self-interest over that of another anonymous player. The amount of money you offered to your partner and your response to your partner's unfair offer are supposed to reflect your cooperative tendency. The additional instructions introduced right before the game were a ruse. In the experimental condition, those instructions were supposed to elicit uncertain feelings, whereas in the control condition, those instructions were modified to elicit certain feelings. We were interested in how people would react in these contexts and how these feelings would influence cooperative behavior. You were told that your compensation would vary from $\$ 0$ to $\$ 10$. In fact, all participants get $\$ 5$. This deception was necessary, because we wanted participants to play the game seriously. Now that you know the true nature and purpose of this study, and you have the option of withdrawing your data from the study. Thank you for your participation! 